\title{
Connecting digital pharma and e-healthcare value networks through product-service design: a conceptual model
}

\author{
Tomás Seosamh Harrington ${ }^{{ }^{*}}$ and Thomas Alexander Burge ${ }^{2}$ \\ ${ }^{1}$ Innovation, Technology and Operations Management Group, Norwich Business School, Faculty of \\ Social Sciences, University of East Anglia (UEA), UK \\ Email: tomas.harrington@uea.ac.uk \\ ${ }^{*}$ Corresponding author \\ 2Institute for Manufacturing (IfM), Engineering Department, School of Technology, University of \\ Cambridge, UK \\ Email: thomas.burge@outlook.com
}

\begin{abstract}
With the move towards more 'outcome' and 'value'-based treatment regimens - increasingly tailored for the individual patient - there is growing pressure on healthcare systems and the pharmaceutical sector to collaborate and co-develop innovative models of care and medication. This paper focuses on the impact disruptive digital technologies may have on the UK Pharma/National Health Service (NHS) ecosystem, and is set within the boundaries of treating chronic diseases. A comprehensive generic model for designing more 'connected' value networks is developed, and validated by an expert panel in the specific case of type 2 diabetes.

An underlying 'disconnection' between e-healthcare and pharma value networks, operating as independent entities, is demonstrated. Moreover, the extant literature details only simple product-fee relationships, without considering the value potential of more digitally connected partnerships. Hence, we explore the potential for emerging product-service system (PSS) concepts involving, for example, health information exchange mechanisms, interoperability and data analytics, wearable technologies, and patient Apps. Scenarios involving more distributed 'make-to-order' service models are also represented by the model - demonstrating the potential for technologies, such as 3D printing, to enable localised and personalised medication manufacture

Underpinned by the literature on digital/loT-based business models and PSSs, the conceptual model reduces complexity and provides practical guidance on future operating principles and protocols to be used in the design and implementation of improved e-healthcare solutions. In turn, this enables stakeholders to better understand potential relationships, serviceable aspects, data flows and revenue streams. Through use of the model, various disparities in key stakeholder perspectives are also captured in this paper. Findings include concerns on the collection and use of patient data, except if partnering mechanisms with the NHS were in place, and when devices/services could be provided for free. Stakeholder viewpoints expressing a preference to be at the centre of data collection, disagreement over data ownership and financial models, and the difficulty in establishing partnerships from a wearables technology provider perspective are highlighted.
\end{abstract}

Keywords: e-healthcare; Pharma, Value Network, Digitalisation, Servitization 


\section{Biographical notes:}

Tomás Harrington is Associate Professor of Digitalisation and Operations Management (Senior Lecturer) within the Innovation, Technology and Operations Management Group at Norwich Business School. Prior to joining the Faculty of Social Sciences at UEA in August 2017, Tomás spent eight years at the University of Cambridge, Institute for Manufacturing. His research and practice interests focus on industrial systems transformation, enabled by the adoption of advanced manufacturing and digital technologies. He has also held senior roles in industry encompassing new product development, process design, and big data analytics - most recently with Intel Corporation. Tomás holds Bachelors and PhD degrees in Chemistry and an MBA (with distinction) for which he received a Chartered Management Institute award in 2008.

Thomas Burge is a Graduate Applied Biomedical/Mechanical Engineer at a major international pharmaceutical company. Thomas works in the (Drug-Delivery) Device Engineering Department and focuses on developing novel parenteral medical devices. Prior to this, he was a student at the University of Cambridge, Institute for Manufacturing reading for an M-Phil in Industrial Systems, Manufacture and Management. His individual research project focused on how the adoption of the loT and wearable devices, within the pharma and healthcare industries, may help facilitate improved treatment regimens for chronic diseases. Thomas graduated from Cambridge in 2016 with a Distinction and the Frederick Alfred Warren class prize. He also holds a First Class M-Eng. degree in Design Engineering from Loughborough University where he achieved three awards for academic performance, including the IMechE Best Student Award in 2015.

\section{Introduction}

As global life expectancy continues to rise, and the prevalence of chronic illness intensifies, the current nature of care is becoming unsustainable. Consequently, there is increasing pressure on healthcare providers to adopt new models of care and medication to meet the individual needs of a growing population (Brach, et al., 2005).

The world is also becoming more 'digitalised'. Emerging disruptive technologies have impacted customer expectations and human factors in ways never seen before: patient demand is not just increasing, its fundamental nature is changing (Jimenez, 2015). Digital technologies are transforming the rules of the global healthcare landscape, making the concepts of personalised medicines, treatments and remote healthcare services a distinct reality (Champagne, Leclerc, \& Hung, 2015). However, radical transformation - with respect to healthcare systems and pharmaceutical industry structures, processes and technologies - is required to embrace this digital era and address the modern issues of growing life expectancy and chronic illness (Taylor, 2015). Future healthcare solutions will require more end-2-end (E2E) collaboration across the value chain, in developing new models of care based around improved patient compliance, adherence and 'personalisation' (Harrington and Srai 2016). Furthermore, Beni (2011) and Ahluwalia, Gimpel, and Varshney (2015) highlight the need for studies on medication adherence within the electronic healthcare research domain.

While a value chain has been defined as "the entire production chain from the input of raw materials to the output of final product consumed by the end user" (Porter, 1980), in studies of the healthcare and pharmaceutical sectors, 'value network' terminology is often used, to reflect activities being increasingly spread across many specialised firms, (Edwards 2009; Harrington, Philips, and Srai 2017). In this study, we argue that despite the increased blurring of industry boundaries (Srai, Harrington, and Tiwari 2016), pharma value networks and e-healthcare systems remain 'siloed', and continue to operate largely as independent entities. Indeed, limited attention has been paid to the role of the 'industrial system' in linking technology developments to final products, and how the design of the value network needs to provide the 'connectivity' between the two (Harrington and Srai, 2017). 
Figure 1 illustrates how digital technologies may conceptually connect industrial systems - in this case, the digital pharma landscape, the e-healthcare system, and the patient.

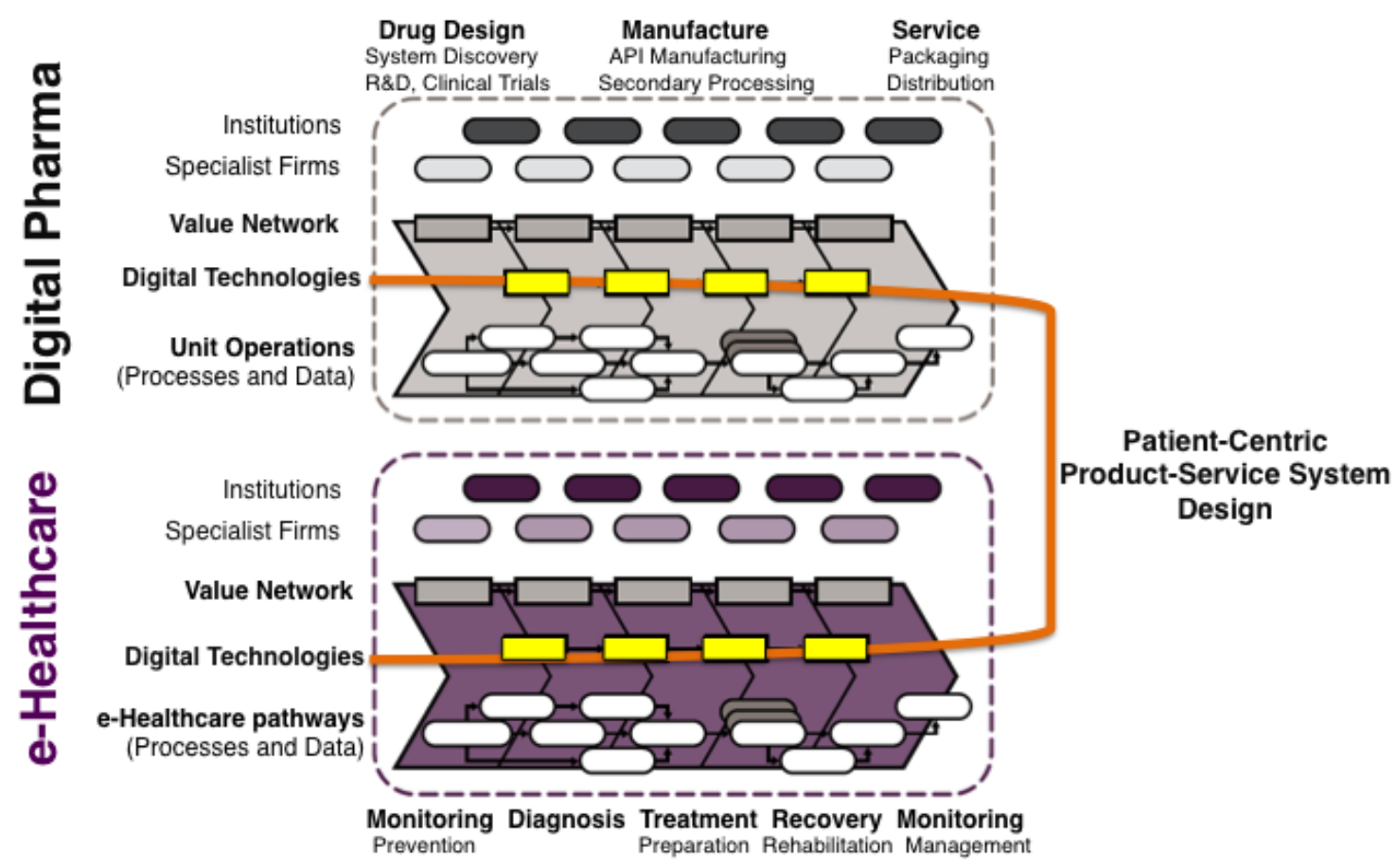

Figure 1. Digital technologies connecting industrial systems - digital pharma and e-healthcare (Adapted from Burns 2002; Porter 2005; Srai et al., 2014; Daly et al., 2015; Harrington, Philips, and Srai 2017)

The pharma/healthcare sector is a challenging environment, regarded as one of the most complex and interesting ecosystems to study, and is characterised by numerous stakeholders and regulations (Campbell, et al., 2000) Shah 2004; Srai et al. 2015). This research challenges the status quo by exploring what impact digital technologies in e-healthcare, coupled with advances (for example) in disruptive continuous manufacturing processes within the pharma sector, may enable. In combination, these could promote more interconnected, holistic and proactive care models personalised to patients and their data. The study is set within the boundaries of chronic disease treatment within the UK healthcare system. Human factors are a distinctive challenge in the state funded system as patients believe they have the right to the best possible care, provided free at the point of access. Another unique feature is that the end customer (individual patient) usually does not understand how the product/drug works, nor do they decide on the dosage or specific variety/brand. Hence, the medicine supply network is characterised by huge complexity, given its highly customised nature, and the unique role of the government who (in the UK) finance the majority of the costs.

The aim of this paper is to define operating principles and protocols in a variety of healthcare contexts where there is a specific focus on service transformation, enabled by a series of emerging manufacturing paradigms and novel business model concepts. A conceptual model representing more connected value networks that are enabled by emerging protocols, is developed and tested. This provides a framework and language for talking about values in the design of e-healthcare systems, and allows designers to directly evaluate the success of specific solutions (Bhartiya and Mehrotra, 2015; Harrington et al., 2016; Midha, Ngafeeson and Ghosh, 2017). Hence, the model simplifies the complexities of the entire ecosystem and aims to enable key stakeholders to better understand potential relationships, serviceable aspects, data flows and revenue streams, previously unconsidered in literature. 
Future service network configuration options, the 'touch-point' processes for better network integration, and the data requirements in supporting the effective implementation of a series of service strategy scenarios can be assessed. These scenarios include the adoption and use of health IT tools, social media, clinical decision support and business intelligence systems that specifically focus on extending 'concepts of operations' and service 'outcome' contracting models to an e-healthcare context (Harrington and Srai 2016). For example, for the provision of care and the treatment of diabetes - we focus on mobile phone technologies and 'product-service' design to develop and test more collaborative E2E solutions that better support self-management by patients. The model can also capture emerging distributed 'make-to-order' service models for pharmaceutical supply-driven by digital manufacturing (continuous processing, process analytics) and supply chain concepts, and 'activated' patients (Harrington and Srai 2016).

Finally, the conceptual model can be used to inform new institutional governance models in ehealthcare-re-defining the role beyond that of traditional regulatory control and governance tasks, to one of being able to facilitate performance 'outcomes' (Harrington et al., 2016). It may promote a more partnered approach involving patients, e-healthcare system stakeholders, and the pharmaceutical sector.

The paper is structured as follows: Section 2 summarises the key literature to inform the development of the conceptual model. Section 3 outlines the mixed methodology used, involving both interviews and an online survey, to gather primary data and develop a model. Section 4 presents the final conceptual model, and its development based on data collected through interviews and survey results. Section 5 presents the conclusions and limitations of the study, in addition to directions for future research in this area.

\section{Literature Review}

This section reviews the academic literature and summarises concepts involving digital technologies and emerging business models. Structured around the following three research themes, these key insights inform the development of the conceptual model.

- Technology developments

- Emerging product-service systems

- Future (digital) business models

\subsection{Technology developments}

Manyika, et al. (2013) report that the top four technologies likely to have the most significant impact by 2025 to be the mobile internet, automation of knowledge work, the loT and cloud computing. For their effective implementation in healthcare, the design and use of technology-enabled systems must reflect the needs, lifestyles, and preferences of patients (Dadgar and Joshi, 2017). The academic literature relating to digital wearable technologies is also growing (Rodgers, et al., 2015; Taylor, 2014; Wang, et al., 2014; Chan, et al., 2012) with multiple applications in the monitoring of cardiovascular, diabetes and respiratory diseases. There are also examples in the literature of mobile phone technology use in improving health outcomes for chronic disease conditions and the self-management of breast cancer, post-hospitalisation HIV and pharmaceutical care (e.g. Sahu, Grover, and Joshi, 2014). While specific parameters to monitor are also well documented (Chan, et al., 2012), the extant literature fails short in addressing what patients value the most in terms of self-management, and how these preferences are designed in (Dadgar and Joshi, 2017). This section briefly summarises technology developments and the role of digital technologies and data in bridging the gap between health providers, the pharmaceutical industry, and patients. 
Major technology firms, such as Google and Apple, are now venturing into the chronic disease monitoring market. Google partnered with Novartis to develop the 'Google Lens' (Barclay, 2014), while Apple has partnered with Dexcom on an App to work with the 'Share2 GCM' device. The sensor (implanted under the skin) transmits data, via a smartphone, to healthcare professionals. It can also allow users to easily monitor their condition through real-time graphs and alerts (Neithercott, 2015). Other proof of principle concepts explored include the 'GlucoWatch $®$ biographer - the first minimally invasive glucose monitoring watch (Tierney, Tamada, Potts, Jovanovic, \& Garg, 2001) - although later banned by the FDA (Chan, Estève, Fourniols, Escriba, \& Campo, 2012). More recently, the FDA has approved two wearable-devices for use in clinical trials. The devices designed by Camntech include the 'MotionWatch 8' and the 'PRO-Diary'. These are intended to acquire and analyse movement data, and can be pre-loaded with survey questions, enabling users to provide feedback throughout the trial (Comstock, 2014). Another recent example is the FDA's approval of a "smart inhaler" that fuses Propeller Health's respiratory disease management technology with GSK's dry powder inhaler Ellipta. A sensor made by Propeller Health is at the centre of this system, and can attach itself to various inhalers to transmit usage information through Bluetooth to a smartphone app. Machine learning then helps synthesise this data to help patients and physicians understand where, when, and why patients use their inhalers ${ }^{1}$.

Digitalisation within healthcare doesn't just relate to wearable-devices, it is about the convergence of multiple technologies (Phillips, Harrington and Srai 2017). Crucially, with a future focus on niche and personalised products serving new and multi-faceted markets, updated distribution and production methods will be required (Srai \& Alinaghian, 2013). A key focus is the loT, defined here as "a manageable set of convergent developments in sensing, identification, communication, networking, and informatics devices and systems" (ECIS, 2009). Hence, it is about the E2E network of objects and sensors that may produce, receive, and share big data (Calia, 2010), as well as the supporting supply chain infrastructure and data analysis required to provide viable care in the future (Kang, 2012; Harrington and Srai, 2016).

The literature relating to the loT and e-healthcare is considered here in three architectural layers, namely the wireless sensor network (WSN), e-Health gateway and the application/back-end system (Rahmani, et al., 2015); (Sun, et al., 2012). The WSN integrates various autonomous sensors, usually incorporated into wearable technologies, into a network of health data collection. The e-Health gateway is concerned with how the associated data is transmitted to an external body (such as physicians). The third layer (back-end analysis) is where physicians may access and analyse the collected data to enable the provision of remote advice. The literature also details various examples of complete e-healthcare solutions (Rahmani, et al., 2015); (Yang, et al., 2014); (Doukas \& Maglogiannis, 2012) and (Dohr, et al., 2010). One example consists of wearable blood pressure sensors, which forward the health data of chronically ill/elderly people, through a smartphone, to physicians. Using sensors equipped in a smartphone, additional data such as activity may be transmitted simultaneously. The physician can then utilise the amalgamated data to monitor health status and adherence, offer advice and optimise treatment remotely. This creates a more effective relationship between the patient and the physician, and enables relatives to remotely care for patients (Dohr et al., 2010).

Finally, Microsoft, Intel and Google are now active in the area of e-health records with their ventures: 'Microsoft Health', 'Dossia' and 'Google Heath' respectively. These platforms may enable customers to store their health records, pharmacy details and additional data on-line, facilitating centralised management and easier access for patients and doctors (Steinbrook, 2008).

\subsection{Emerging product-service systems in pharma/healthcare}

The product-service system (PSS) concept (Vandermerwe and Rada (1988) has already been comprehensively reviewed in the literature (Baines, et al. 2009). In this study, we focus on a series of PSS types proposed, namely 'Product-oriented', 'Use-oriented' and 'Result-oriented' (Neely, 2009).

\footnotetext{
${ }^{1}$ https://www.rdmag.com/article/2016/11/fda-grants-approval-propeller-healths-smart-inhaler
} 
This captures a product-service spectrum ranging from customers owning a tangible product with addon services (such as maintenance), through to the sharing and leasing of products, and services that completely replace product ownership (voicemail services). In addition, we introduce two more recent variations from the literature - 'Integration-oriented' and 'Service-oriented' (Yip, Phaal, \& Probert, 2015).

The complexity and difficulty of adopting PSSs is also well reported in the literature (Neely 2007; Ryan et al., 2014). For 'consumers' in healthcare (payers and patients), PSSs can mean a shift from buying products to buying services and solutions, requiring higher levels of engagement. For manufacturers and service providers, the concept results in a greater degree of responsibility across a product's life cycle, (Harrington and Srai 2012). It also needs to involve consumers earlier in both the design of the product and system (Mont, 2002) (Dadgar and Joshi, 2017).

In terms of Pharma, Taylor (2014) reports that the sector has long been considering a transition from product-oriented business models to alternatives more closely focused on serving the needs of patients. 'Equally Zeneca' (now 'AstraZeneca') after acquiring 'Salick Health Care' in 1997, operated a fully integrated cancer and chronic care service in the US, which facilitated performance monitoring of their own and competitors' drugs (Howells, 2000). Another example in healthcare is 'GE', who have a maintenance based PSS for their CAT and MRI imaging products (More, 2001). The rapidly changing landscape in the fields of communications, Internet and social media makes it imperative for professionals to better understand the role of Information and Communication Technologies and their impact on everyday activities (Apostolakis et al., 2012).

Despite the fact that the concept holds great potential to address major challenges within healthcare , PSSs are relatively unexplored in the literature (Mittermeyer, et al., 2011) with limited examples reported (Yip, et al., 2015); (Ryan, et al., 2014); (Velikanov, et al., 2013) (Köbler, et al., 2009) and (Ajai, et al., 2009). In the context of this study Ajai et al., (2009) detail the design of a results-orientated PSS for point-of-care devices, with a case study to collect and transmit health data back to healthcare professionals, enabling the provision of remote services (see Figure 2). Blood test reminders and external analysis of results are provided as serviceable aspects made possible through more of a 'closed system'. There is also limited literature discussing the potential for a PSS model spanning both healthcare and pharmaceutical sectors. While Mittermeyer, et al. (2011) report a comprehensive case study, detailing B2C and B2B relationships and product/service components of a drug/device combination, it does not contain any reference to wearable devices and loT, or base any serviceable aspects on digitalisation. 


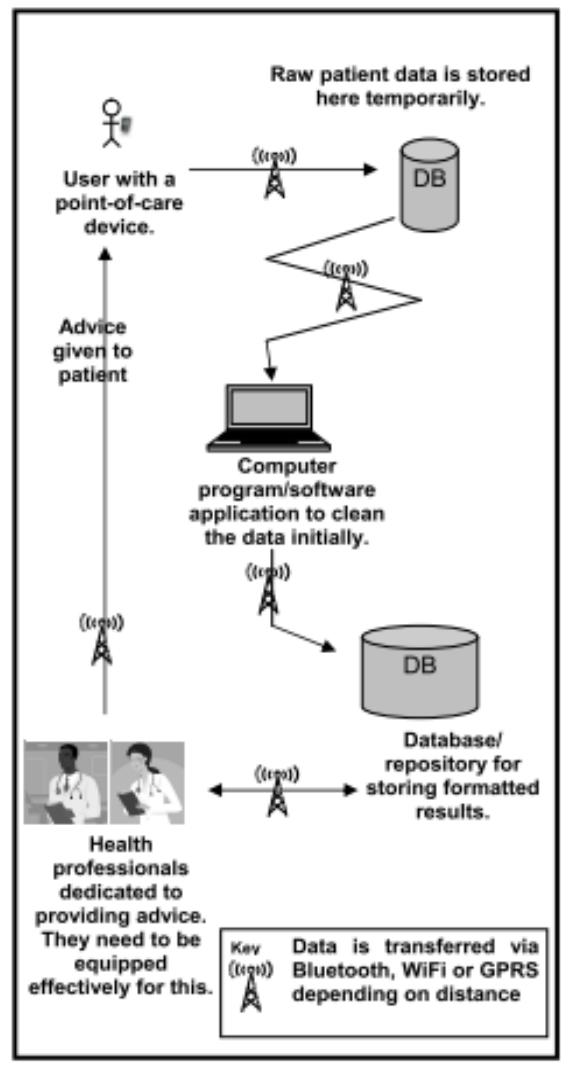

Figure 2. Schematic of a product-service system for point-of-care devices (Ajai et al. 2009)

\subsection{Future (digital) business models}

Digital/loT-based business models are relatively few, with limited frameworks currently reported in the academic literature (Osterwalder and Pigneur, 2010; (Fan \& Zhou, 2011) (Sun, et al., 2012) (Dijkman, et al., 2015); Chan, 2015. Liu and Jia (2010) present a detailed overview of where loT could be applied, proposing two business model framework variations in a healthcare context. The authors also highlight the key actors involved in the drug supply chain and their value interfaces (flow of goods, services and finance). Figure 3 illustrates one of the two model variations that focuses on the terminal equipment provider'. Both models proposed by Liu and Jia (2010) demonstrate a distinct disconnect between the drug manufacturer (pharma) and the patient, with little to no interaction or feedback detailed between the two. This was a recurring theme across this literature review, and is also echoed in the supply chain literature (Pedroso \& Nakano, 2009). Most models primarily concentrate on how IoT could help drug manufacturers optimise inventory and supply processes, whilst assisting hospitals improve the traceability of drugs. The extant theory does not detail how both pharma and healthcare collecting and sharing data through the loT - could enable services (such as personalised medication and/or remote treatment). In addition, there are no protocols or operating principles detailing how data could be collected and transmitted. Moreover, the literature details only a simple product-fee relationship between the two industries, without considering the value potential of more digitally connected partnerships. 


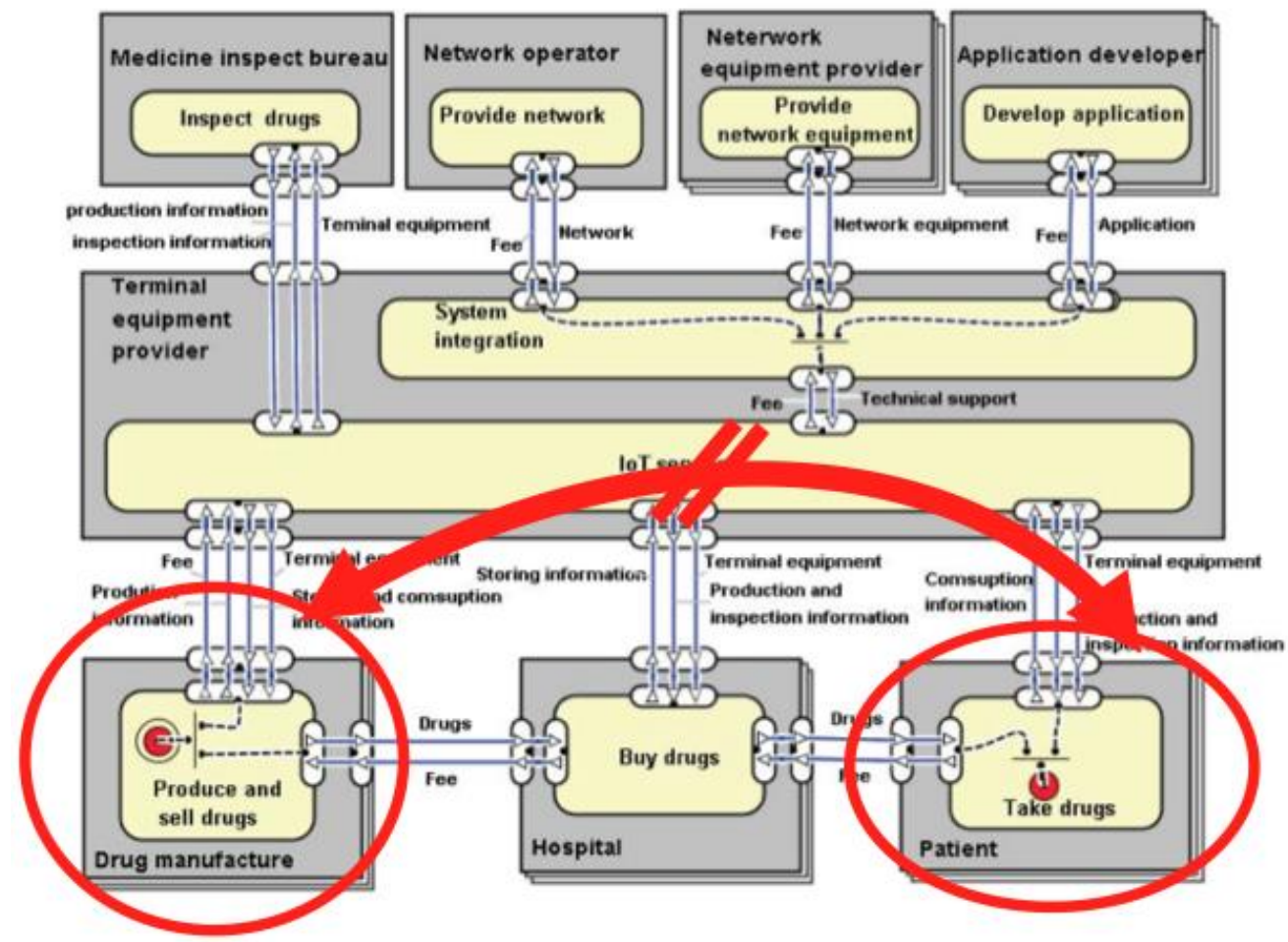

Figure 3. Drug supply chain loT business model - illustrating disconnection between pharma and the patient (adapted from Liu and Jia, 2010)

The concept of a digital supply chain has been described as being a smarter supply chain that can interact with customers throughout the entire product lifecycle - prioritising flexibility and visibility (Chen, Long, and Yan 2004; Butner 2010; Harrington and Srai, 2016). In order to address several issues within pharma and healthcare, a large body of literature is starting to emerge on the adoption of digital supply chains (Zhou, Chong, \& Ngai, 2015); (Narayana, Kumar Pati, \& Vrat, 2014). For efficient and effective implementation of more digitalised supply chains, the literature principally stresses the need for data driven business models to resolve issues of collaboration and coordination between players (ibid).

\subsection{Research Gap Identification}

Patient-centric healthcare subscribes to the belief that the patient has values that are important in the healthcare experience, and in the relationship between those providing care and the patient (Puustjarvi and Puustjarvi, 2011). Extending this idea to incorporate the role of digital pharma, the research objective of this study may be defined as 'exploring the potential for a patient centric, connected value network, based on digital technologies (continuously collecting and communicating patient data), in order to promote 'personalised' treatment for a specific patient population.'

The primary gaps identified from the academic literature relate to the roles key stakeholders may play in the digitalisation of healthcare and in the treatment of chronic illness. There was also little evidence on how emerging digital technologies may better integrate the pharma sector with patients and healthcare providers, how a more connected system could be structured, or what value this could generate for each stakeholder. Similarly, limited literature exists that examines PSSs in the context of pharma and none explore how PSSs, combined with the loT, may influence business models and/or value capture. Questions such as: who would pay for the technology; who would own the data collected; who could use/share the data; what outcomes could be targeted with the data, are currently 
unanswered in the literature. Here, understanding current and future configurations is critical when exploring the relative attractiveness of potentially disrupting technology interventions in medicine manufacturing and healthcare management, and ensuring consistent "like for like" business case comparisons (Settanni et al., 2017).

From a practical perspective, the use of mapping techniques can serve to reveal the main interactions and linkages between emerging constructs (Srai 2017). In the case of electronic health records - Samhan and Joshi (2017) used mapping techniques to uncover underlying concepts that are shaping a series of constructs identified as being critical; costs, benefits, perceived value, perceived threat, organisational support, self-efficacy, and system circumvention availability. While limited literature has considered both pharma and e-healthcare constructs, in unison, a basic conceptual value network for the adoption of e-commerce in pharma has previously been developed (Allee 2000). Appendix I illustrates this framework for mapping and clearly articulating the flow of goods, services, revenue and knowledge between actors.

Building on the gaps identified in the literature and the mapping approaches outlined here, section 3 now sets out the methodology and process in developing the conceptual model.

\section{Methodology}

Figure 4 outlines the development of the conceptual digital value network model. Building on the gaps identified in the literature and the mapping approach in Appendix I, a mixed methodology involving both interviews and an online survey was employed to gather primary data. Both interview and survey methods were selected to gather as broad a range of perspectives within the ecosystem as possible. Utilising the two separate sources of data also allowed for better data triangulation and increased the validity of findings (Eisenhardt \& Graebner, 2007). Interviews were employed to collect rich, empirical data and capture the viewpoints of pharma, device manufacturers, the UK's National Health Service (NHS) and academics (Eisenhardt \& Graebner, 2007). They were also used to explore emergent themes and to better understand the evolution of the ecosystem. Conversely, the survey sought to source a broader pool of data, to represent the general public's views and enable a comparison with the interview findings. The methods were employed contemporaneously with findings used to dynamically refine/improve the questions, where applicable.

As outlined in figure 4, the interview process consisted of two stages: The first stage involved a pilot to test and refine the structure and wording of the semi-structured interview questions. Stage 2 involved data collection through in-depth interviews with an expert panel (see Appendix II), to ensure appropriateness. This panel was specifically selected to support initial validation of the conceptual model in a UK context. Criteria included: individuals who were globally recognised in their domains of expertise; were currently in post, or recently held, a senior managerial and/or technical role; had relevant experience and knowledge of pharma, healthcare, wearable devices/technology, and/or regulatory bodies; had expert knowledge and understanding of chronic disease(s) and respective treatment(s) in a UK context; had access to an international network of experts.

Viewpoints from the expert panel were captured and analysed, using qualitative content analysis, to inform the development of the conceptual digital value network model. Qualitative content analysis was used to extract relevant information, separating it from the original text, and processing only the information that was relevant to inform the development of the conceptual model. This specific analysis approach was selected as the research objective of this preliminary study could be answered without processing knowledge about the form of statements and position in the text (Kohlbacher 2005; Gläser and Laudel, 2013).

The survey questions were developed to support the interview process, and refine the conceptual model. As outlined in figure 4, an online survey was designed and made active over a period of two months - from late-June to mid-August 2016. This built on the interviews by capturing data to represent the patients' perspective. It was targeted at the general public and avoided potential ethical issues of interviewing patients directly. A process, proposed by Forza (2002), was adopted in developing the survey. Initially, a draft set of questions (informed by the literature review) was tested 
on a population of six people. The survey next went through a process of refinement to ensure it was intuitive, was consistent with the respondents' level of understanding, would take less than 10 minutes to complete, and afford valuable data (Forza, 2002).

The survey was digitalised using the website 'www.smartsurvey.co.uk' enabling the use of advanced question styles (such as matrix and ranking scales). This reduced the number of questions and time required for completion. The structure was as follows; section one (after an introductory page) focused on wearable-devices, the second on data collection, the third on business models/services, and finally on general demographic details. Question styles were predominantly closed with pre-defined options to enable quick data collection and simple quantitative analysis (Forza, 2002). The option of 'other' was included where relevant, along with a comment box for expression of alternative or additional views. The introductory page also highlighted the fact data would be collected anonymously and for research purposes only. Before official release, the online version was again trialled using a larger group of 12 people. This further confirmed intuitiveness, and correct and concise wording of questions to ensure key data was captured (Leung, 2001). In total, 122 responses were received from the online survey. In reviewing the data, it was found five respondents had not completed the form correctly and were consequentially excluded, leaving 117 for analysis. The population included roughly an even split of males to females. Five suffered from diabetes and 16 suffered from other chronic illnesses. The final survey design is included in Appendix III. 
Figure 4. Methodology and model development: investigative phase exploring key insights derived from the academic literature, supported by data collection (interviews and survey), and final expert panel assessment

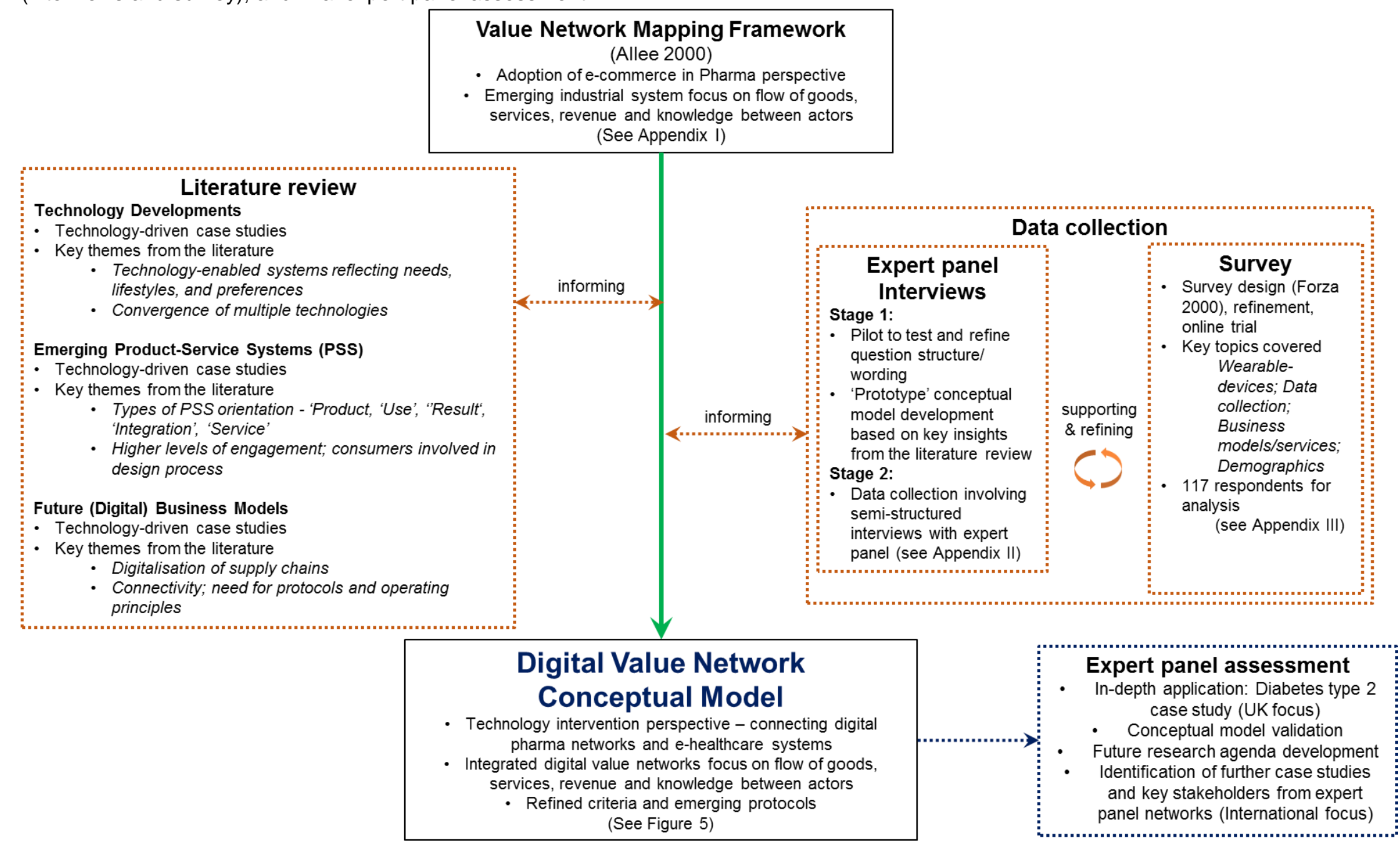




\section{Digital Value Networks - Conceptual Model Development}

As industrial systems become more collaborative and service-based, the value network concept is increasingly seen as a valuable mapping and modelling technique to represent such complex ecosystems (Peppard and Tylander, 2006; Srai et al., 2016; Settanni et al, 2017). Based on the process outlined in figure 4, the framework proposed by Allee (2000) was adapted and extended to develop a comprehensive model to explore alternative digital value network options.

Multi-layer analysis is rarely adopted in the literature, but is stressed by Gupta, et al. (2007) as vital to adequately understand how organisations operate within industrial ecosystems. The model was therefore structured in a multi-layered fashion, detailing both internal and external relationships within and between entities, and demonstrating nuances in data flow. The final model presented here has been structured around a joint venture (JV) scenario involving the NHS and a wearable technology company - see figure 5 . As well as key stakeholders such as the NHS, device/technology companies and regulators, the model captures various disparities identified from both the pharmaceutical sector and patients. The key model developments are detailed first in subsections 4.14.4. How these developments are supported, by the expert panel and survey, are then outlined in the data collection discussion section (section 4.5.).

\subsection{NHS/Technology Company Joint Venture scenario}

In this digital value network scenario, the JV forms the central data collection and analytics entity. This was based on the publics' preference, expressed through the online survey, for the NHS to collect and analyse their data while drawing on the necessary expertise and rapid innovation capability of an established technology company. A JV is the favoured approach here as it was emphasised - through the expert panel interviews - that the NHS would not be able to move fast enough on its own to establish the infrastructure and analytical ability that such a partnership would enable. In this PSS scenario, data could be processed within this entity and distributed to healthcare professionals to enable the various remote services detailed in figure 5. Data indicating any adverse events could be delivered to the Medicines and Healthcare products Regulatory Agency in the UK (MHRA) ${ }^{2}$ in order to comply with existing (and/or emerging digital) standards. In addition, data could also be shared with specific pharma companies, after individual patient consent has been obtained. This data could contain condition-specific, medication reaction details and additional information to enable stakeholders to ascertain value and effectively provide personalised medication. To address concerns expressed by the public in the survey, the data could be anonymised and encrypted, ensuring only the $\mathrm{NHS} /$ pharmacies could identify patients.

\subsection{Inclusion of Automated Pharmacies}

Automated (online) pharmacies were incorporated into the model to address voiced legislation concerns, and to act as an intermediary between the pharma sector, device companies and the patient. Patients could automatically receive personalised medicine and wearable devices from said companies, in exchange for digital prescriptions (supplied via GPs), without requiring manual collection. An example of such a service is already offered free by 'PillPack' in the US ${ }^{3}$. PillPack organises and delivers patients' medications, daily by the dose, and automatically takes care of refills. The automated ordering process could be facilitated via a replenishment request, sent from a wearable-device, to both pharmacy (PillPack) and the pharma organisation - enabling better sales volume forecasting. Scenarios involving re-distributed and continuous drug manufacture have also been captured by the model, demonstrating the potential for technologies, such as continuous flow

\footnotetext{
${ }^{2}$ https://www.gov.uk/government/organisations/medicines-and-healthcare-products-regulatory-agency

${ }^{3} \mathrm{https}: / /$ www.pillpack.com
} 
and 3D printing, to enable localised and personalised medication manufacture - potentially at the pharmacy (EPSRC, 2013; Srai et al, 2016).

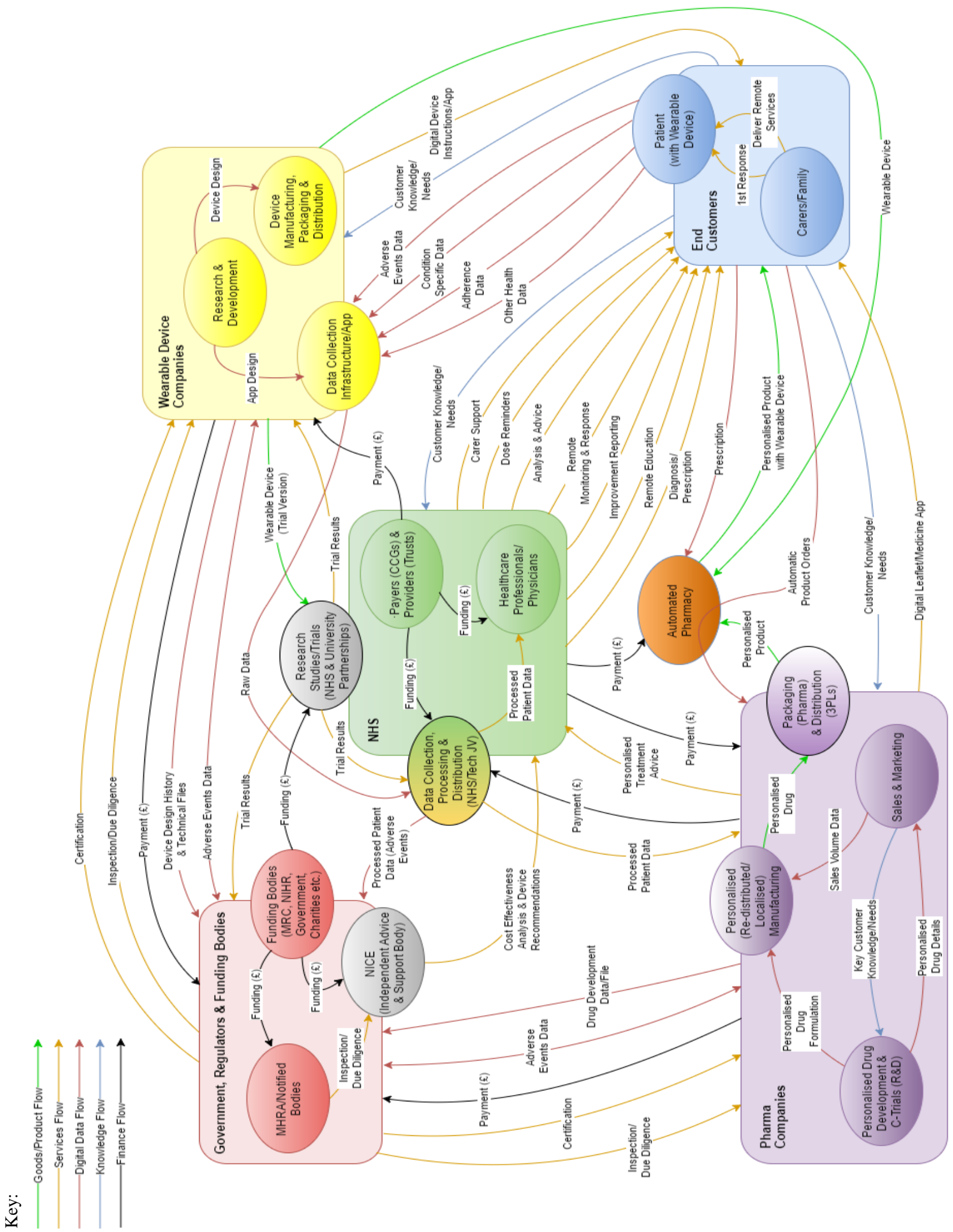

Figure 5. Conceptual model - in designing more 'connected' value networks 


\subsection{Finance Models and Cost Effectiveness/Safety Analysis}

Based on feedback from the expert panel and survey respondents, it is proposed that the supply of wearable devices, personalised medication and the majority of remote services be funded by the NHS. To justify the required expenses, the cost effectiveness of devices would first need to be calculated by the UK's National Institute for Health and Care Excellence (NICE) ${ }^{4}$. This independent body could take data generated through research studies/trials (completed by university/NHS partnerships) and the MHRA, evaluate the value proposal and make the required recommendations to the NHS. It was agreed by the expert panel that the devices could offer substantial value by reducing the cost and number of chronic-disease related emergencies. In turn, this could both lower the demand on GPs/physicians, and reduce patient suffering.

Based on insights from the survey results, patients would not be paid for their data, but could be given the option in their initial GP prescription consultation to opt-out of a data collection scheme. It was also suggested by the expert panel that patients could be given a choice of device features (e.g. colour, design and functionality), which could in turn encourage correct use/adherence. Personalisation and/or increased functionality could be offered for a fee.

\subsection{Incorporating Carers}

Patients with chronic conditions make day-to-day decisions about the self-management of their illnesses (llioudi, Lazakidou, and Tsironi 2010). Carers/family members have been incorporated into the model as, depending on the patient's condition, certain services may be received and delivered via these intermediaries. An example of which could be informatics tools, targeted at multiple user groups, to support health outcomes and provide greater independence for older patients (Le et al., 2012). The digital value network model demonstrates how both patients and carers could receive services/warnings simultaneously, potentially enabling carers to continuously monitor patient conditions and be their first point of care in emergencies.

\subsection{Survey/interview results discussion and implications}

The overarching theme emerging from the analysis was the level of disparity in a series of stakeholder viewpoints. This supports previous research on uncertainty and transformational challenges - in terms of opportunity areas, technological readiness and a future vision for the pharma/healthcare sector, as a whole (Harrington, Phillips, and Srai 2017). Consequentially, when developing the conceptual model, numerous challenges and conflicts of interest had to be considered when encompassing the social and economic perspectives of key stakeholders (Jeansson, 2013; Harrington et al., 2016; Dadgar and Joshi, 2017). Hence, a descriptive analysis on the survey data was performed to gain greater understanding of emerging constructs, needs, and values. In turn, this aided the development of a common language across the various stakeholders, which directly relates to the proposed model and its information flows. Key findings, and links to model development, are now outlined in sections 4.5.1-4.5.4.

\subsubsection{Data Collection and Use}

It is clearly evident that both the NHS and the pharma sector are actively pushing the adoption of digital technologies. In the conceptual model (figure 5), the PSS depicts raw patient data being collected/sent via a mobile app before entering the JV to be processed. This app may be regarded as semi-external to the wearable devices entity - to imply it could be supplied and created via a separate wearable device company, or be included as part of the JV. This semi-external structuring is also

\footnotetext{
${ }^{4}$ https://www.nice.org.uk/
} 
intended to indicate that the company providing/maintaining the app would not necessarily have access to patient data before it is processed by the JV.

There was a general acceptance that wearable devices and Apps represent significant value opportunities to patients and companies. Numerous examples of the NHS and specific pharma organisations looking to partner, or already partnering, with a range of technology companies was also discussed.

The need for pharma and/or the NHS to form partnerships with such companies was emphasised, particularly in the short term, to acquire expertise and the ability to innovate rapidly. However, the difficulty of establishing the aforementioned partnerships was highlighted from a wearables/technology provider perspective. Key barriers identified by the expert panel included bureaucracy, lack of available financial backing and the notoriously low acceptance of new, risky technology by the NHS as key issues.

Critically, the majority of parties interviewed expressed their desire to be at the centre of data collection. From the NHS perspective, "third parties are not needed, third parties add cost and complexity", hence, healthcare providers would be best suited to provide data-based services. Likewise, from the perspective of pharma/wearable device companies, collecting primary data was seen to be in their best interests to develop superior drugs/products, improve supply chain design, and enable services such as personalised medication. However, there was a clear preference for the NHS over the other options by those surveyed. One respondent added: "I don't have much trust in pharmaceutical companies, so I wouldn't want them to access my data". This perception of pharma was a common theme observed throughout the survey and interview process (figure 6).

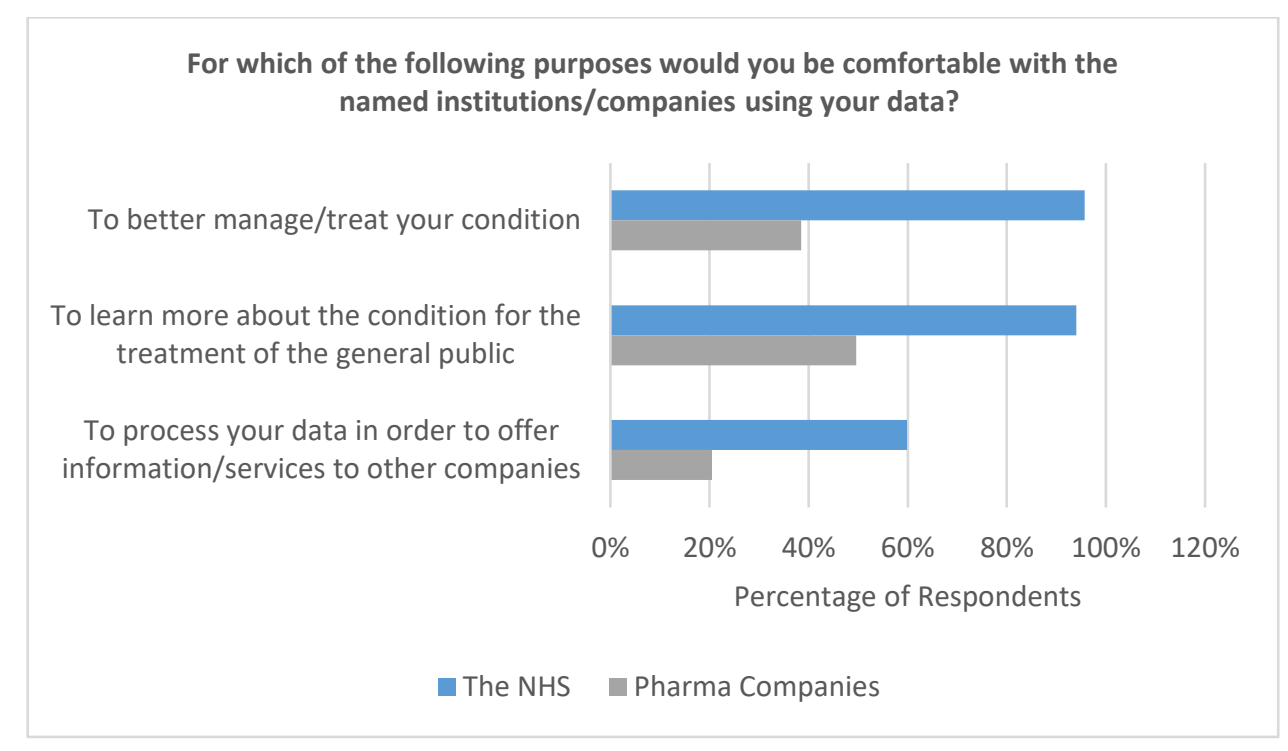

\section{Figure 6. Data use preferences}

Based on these insights, the concept of a JV between the NHS and a technology company appears to be the most appropiate and viable solution. However, a concern highlighted by the NHS with this scenario was the issue of additional clinical responsibility and implications of data collection. Interviewees added that "when you are monitoring the uploaded patient data, your duty of care to that patient is 24/7". This would potentially incur additional staff training and emergency response requirements to use and act on data correctly - "does the NHS have the capacity to be responsible?" This highlighted the need for greater industrial collaboration - partnering with technology companies may facilitate more effective data processing and put in place technological solutions to assist the NHS in handling such complexities.

From a pharma sector perspective, it was highlighted that simply gathering disease-specific data would not be sufficient - "I can't see how just the reaction to the drug is enough to get huge value". Additional data, such as medication and activity details, would also be required to enable meaningful analysis. Data quality and reliability were also seen as vital for any analysis to be valuable and utilised 
safely. Here, the survey results indicate that a large majority would be comfortable with the NHS collecting such data, as summarised in figure 7 . However, it was made clear through discussions with experienced medical professionals that the NHS would not have the required knowledge or infrastructure on its own to extract value, thereby, further justifying the need for increased collaboration.

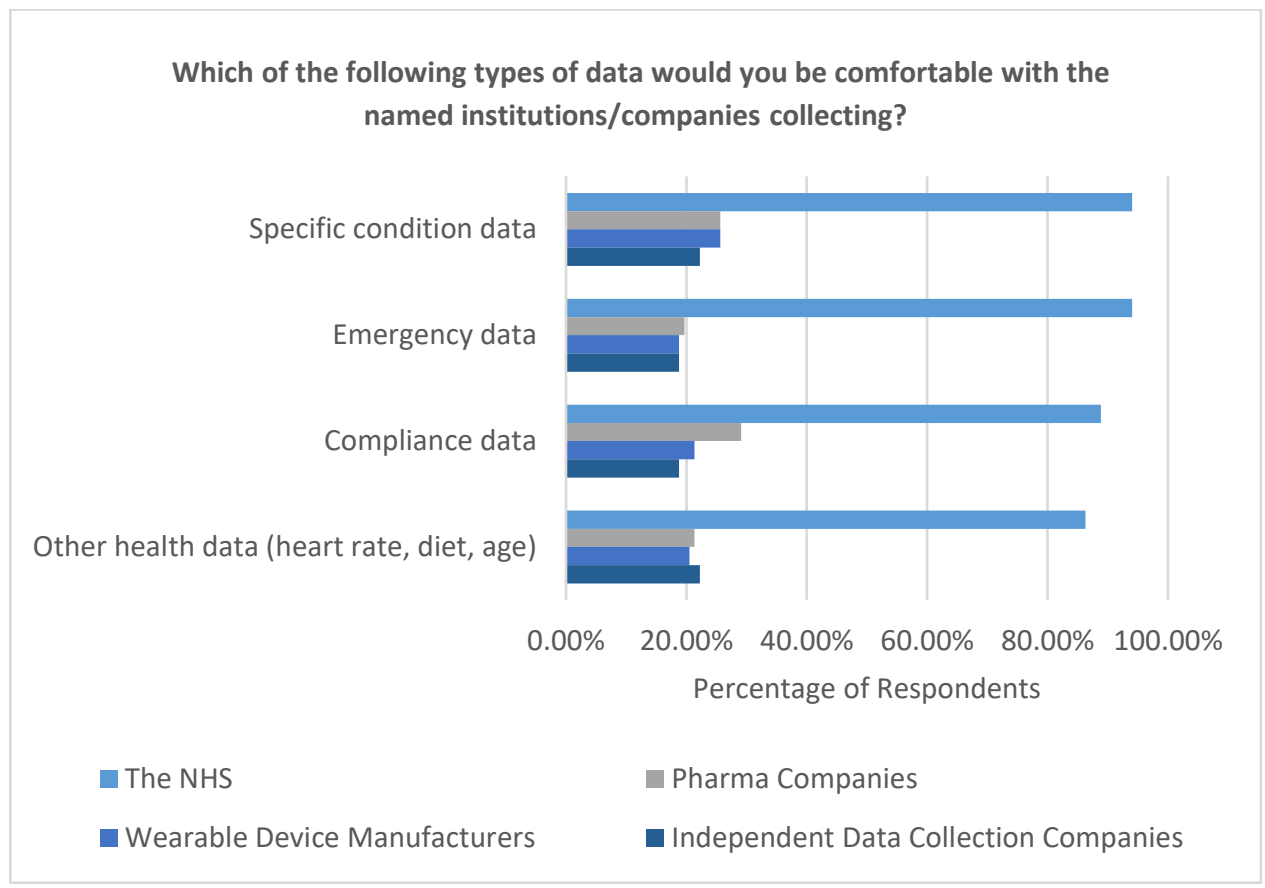

Figure 7. Data collection preferences

While data ownership was found to be a topic of uncertainty and disagreement, the general consensus was that patients should own their data. It would therefore be the patients' right to decide who could access it, and whether to charge for its collection. It was emphasised that patients are also generally protective of their data and are unwilling for it to be shared without permission. The case of the 'care.data scandal' was cited as precedent (BBC News, 2014)5.

The majority of people surveyed would be happy to wear a data collection device, with only $2.5 \%$ stating otherwise. In terms of features - comfort, lightweight in nature and non-invasiveness were found to be the most critical for such a device. However, despite the majority of survey respondents expressing their acceptance of wearable devices both monitoring and automatically administering medication, the latter is not recommended and excluded from the model. This is primarily due to concerns expressed in interview that this would cause devices to be deemed as 'class 3', significantly increasing costs and regulatory burden.

With respect to key outcomes from data collection, respondents ranked improving their own conditions through better management/treatment and personalised medicine as the most vital. Ensuring anonymity of data was ranked third with respondents highlighting the importance that data could not be used by non-NHS organisations to identify them. Interestingly, receiving a fee for their data was seen as the least important option (out of 7 options).

\subsubsection{Services}

Both the NHS and pharma organisations were interested in establishing new personalised medicine ventures and adopting more data-based services. In addition to "providing to the NHS more than just

\footnotetext{
${ }^{5}$ http://www.bbc.co.uk/news/health-26259101
} 
drugs", this could involve consultation to help develop optimum personalised treatment plans for rare conditions.

In the academic literature, education is presented as being critically important, but it is often missing from available mobile Apps (Taylor, 2015). Both the NHS and pharma expressed an interest in offering remote education services, with the newly developed 'My COPD' exemplified. My COPD is a free NHS 'self-management App', developed by a third-party, which will provide remote instruction on taking medication, reminders, and a mechanism to monitor adherence. NHS professionals stressed the importance of such Apps to "give the responsibility back to the patients and to support and educate them in terms of self-management". A suggestion from the pharma perspective would be to provide a mobile App/digital leaflet, accessed by scanning a unique code on a patient's medication with a smartphone. This could facilitate services, such as easily accessible disease and personalised medication information. It was also highlighted that carers and family members are important stakeholders to consider as many chronically ill patients would rely on others to deliver the digital services. In addition, services focused on carers, such as remote support or alerts if patients were to need assistance, was recommended. Figure 8 illustrates that the majority of respondents (95\%) would be content in receiving remote data-based services from the NHS, as opposed to pharma organisations.

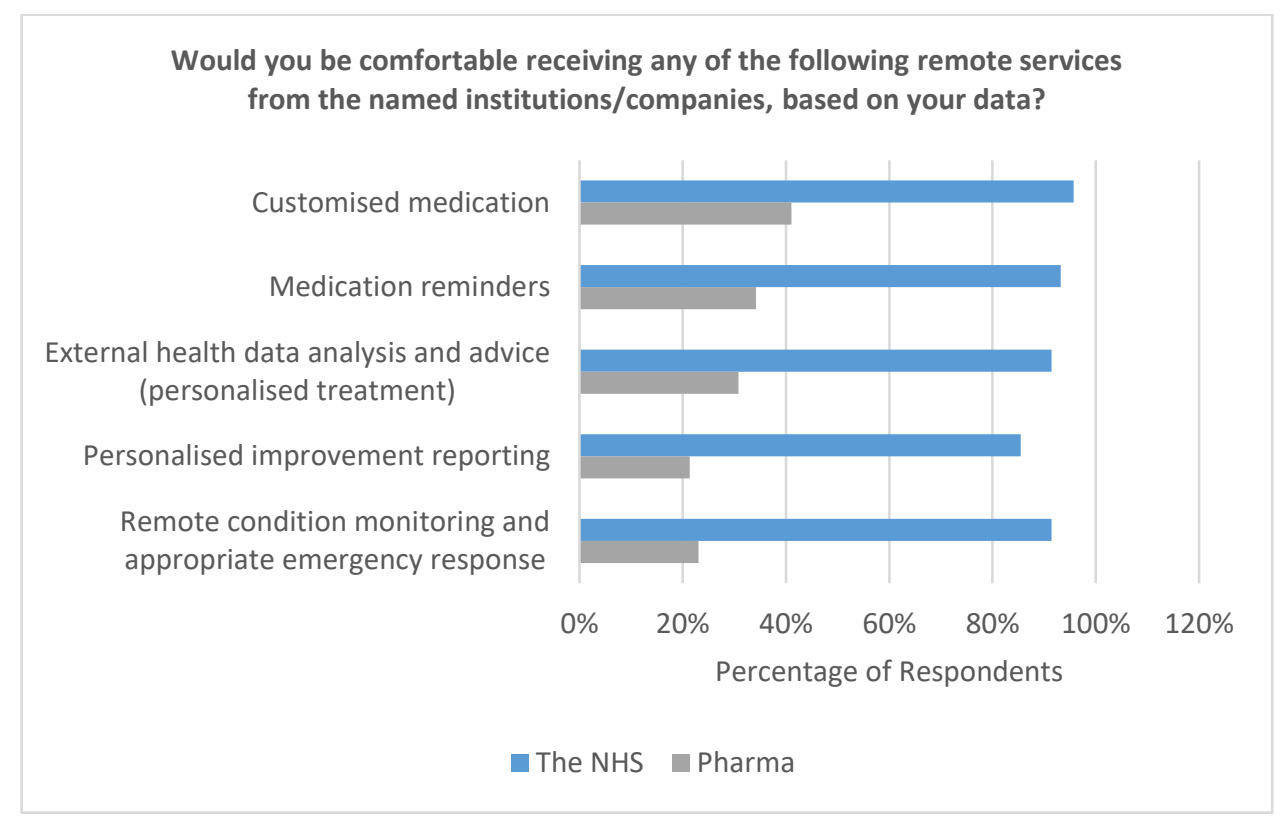

Figure 8. Remote services preferences

Furthermore, $55 \%$ were willing to pay a reasonable fee. Although this figure was lower for pharma, $71 \%$ of respondents still stated they would accept services from such companies with $35 \%$ also being prepared to pay (figure 9). Only $29 \%$ stated they would not accept free or chargeable services from pharma in this particular case. Moreover, it was found the majority of respondents would be comfortable with pharma partnering with the NHS to tackle chronic conditions, on the condition that they would not be charged for devices or services. Less than $35 \%$ would be prepared to pay anything to help improve the treatment of their condition. 


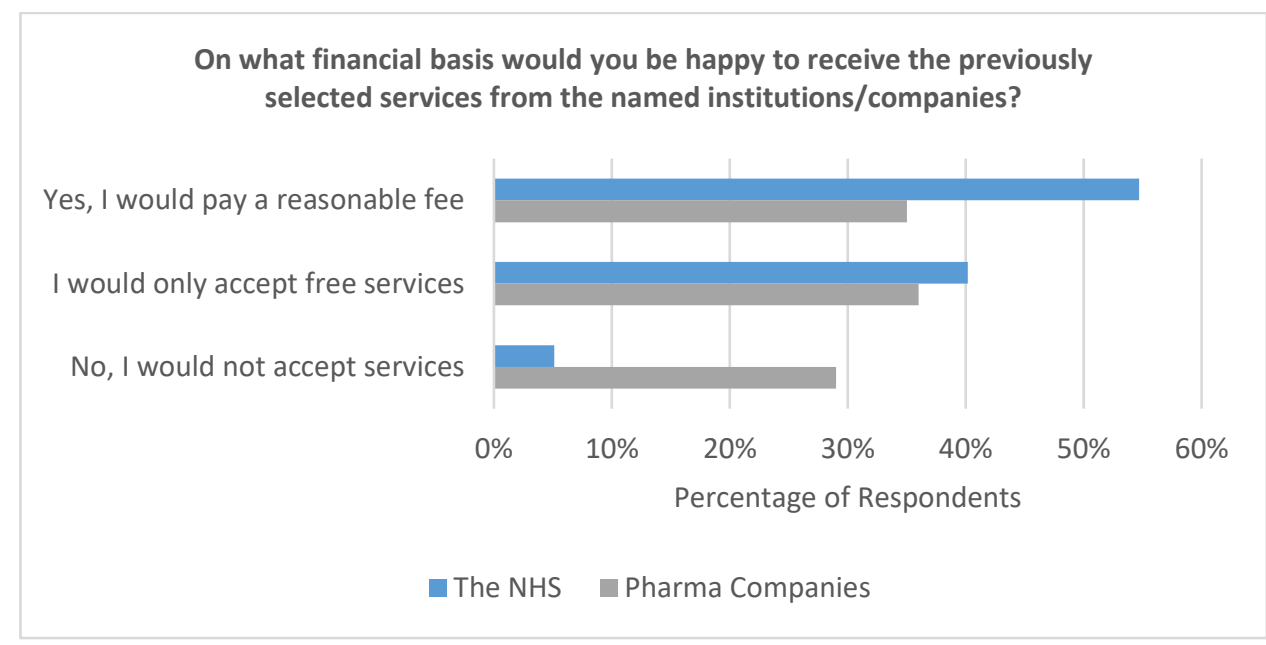

Figure 9. Fees and services preferences

Based on these findings, the opportunity for services across the various stakeholders was incorporated into the model in a manner that most appropriately addressed the preferences/concerns of the public, the NHS and industry. Given the perceived lack of trust expressed by the public (and regulatory concerns highlighted) the concept of a digital leaflet/app is the only service proposed to be offered directly by pharma organisations to patients. In addition to pharma providing such services for personalised instructions and education, technology/wearables companies could also offer equivalent services for devices.

\subsubsection{Finance and Payment Models}

The financing structure, captured by the conceptual model in figure 5, was based on insights from a series of stakeholders. Some disparities were identified - one NHS practitioner/academic suggested that "if you give someone something for free, they don't value it", which would potentially result in improper use or damage; another correspondent stated that "you can't have a system that has such inequity of accessibility", in that only the affluent could afford it.

From the device developer perspective, the majority of income comes from services and it would be infeasible to provide free devices (due to the large initial capital required). Nevertheless, the most common view was that patients should not be charged for devices or services (because the majority of chronic disease sufferers do not pay for prescriptions due to their age). The general view expressed by pharma/NHS was that they would not be willing to pay patients for their data (outside of clinical trials) as this could be seen as unethical, particularly in the case of pharma organisations. Figure 10 summarises the survey results on finance models, with preferences informing the development of the conceptual model. 
If pharma companies and the NHS were to partner in a new initiative to tackle chronic conditions, which arrangements would you be comfortable with?

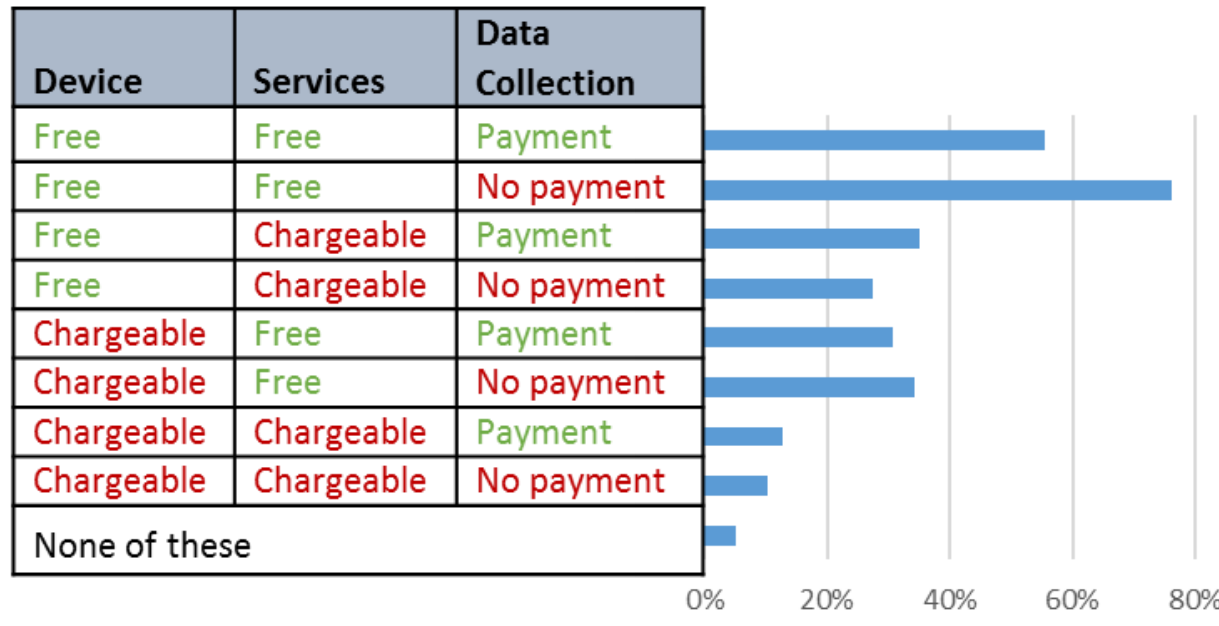

Figure 10. Finance model preferences

Other interview/survey insights supporting the development of the model centred on data being collected and services being offered by the NHS/technology company JV. Here respondents indicated they would be happy for the NHS to benefit financially from their data, but not the other listed organisations (see figure 11). Furthermore, 31\% stated they would not be happy for any entity (including the NHS) to benefit financially from their data, stressing it should be used purely to improve peoples' health and not for profit.

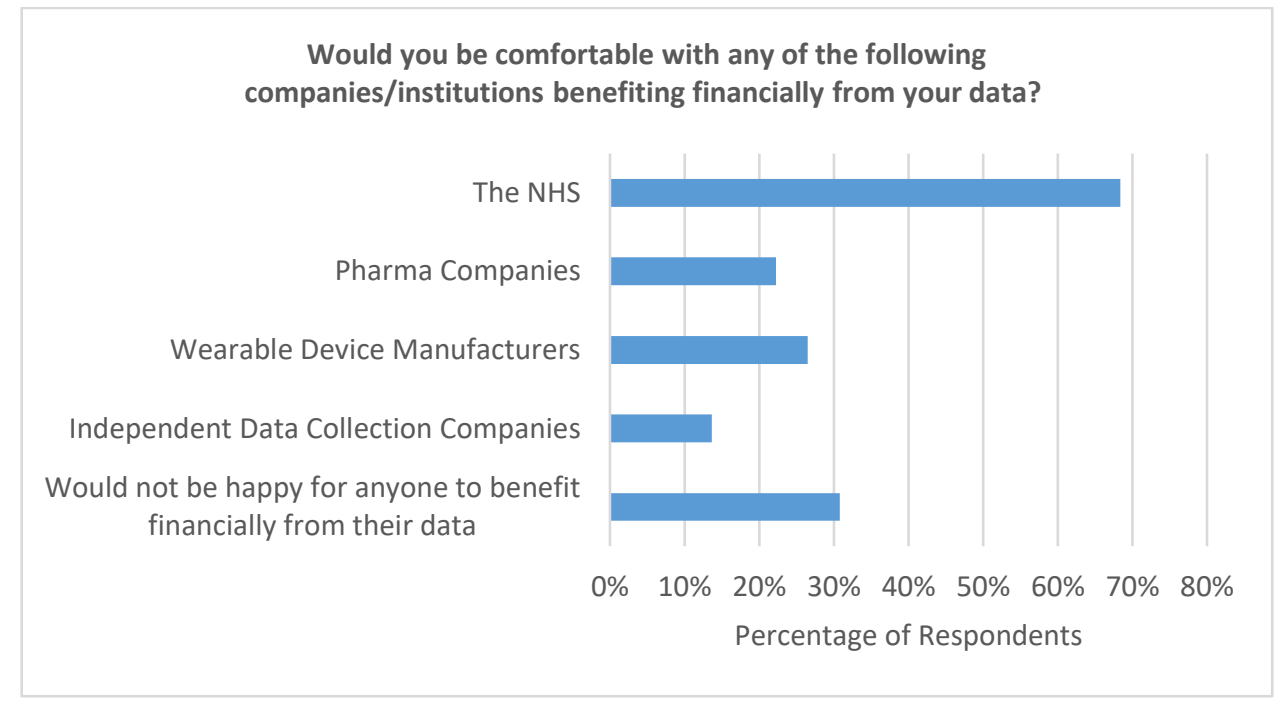

Figure 11. Finance model preferences

A key theme highlighted, from the perspective of the NHS, was that of 'cost effectiveness'. It was emphasised that unless there is a clear value proposal for the NHS, then recommendation by NICE for incorporation would be unfeasible. Furthermore, research studies/clinical trials partnerships between the NHS and universities would be mandatory to test new technologies and provide NICE with data on which to base their analyses. These partnerships, along with NICE and MHRA, would have to be funded via bodies separate to Clinical Commissioning Groups (CCGs), such as the Medical Research Council (MRC) or the National Institute for Health Research (NIHR). 
A key theme communicated and incorporated into the model was the likely challenge of legislation in establishing a digitally connected ecosystem. It was argued that pharmacies may always have a role to play in the network due to current laws governing drug prescription/supply. There were conflicting views on whether legislative changes could potentially make pharmacies redundant in the future. There was also concerns and disparity over regulations that focused on how pharma organisations may interact with patients - highlighting direct marketing and inducement as inevitable challenges.

Data security and confidentiality were recurring themes with all parties mindful of the potentially severe consequences of customer data being hacked, historically leading to lawsuits or fines. The NHS partnering with a technology company, and having access to their cybersecurity knowledge/infrastructure, was therefore seen as a safer option than operating individually when collecting patient data.

\section{Discussion and Conclusions}

Digital technologies are becoming increasingly more disruptive and are facilitating a new age of ehealthcare based on remote data collection and analytics. Future e-healthcare solutions will require more end-2-end (E2E) collaboration, in developing new models of care based around improved patient compliance, medication adherence and 'personalisation'. As a result, more 'connectedness' between e-healthcare and digital pharma is required in order to promote future value-based medicines and services tailored for both patient populations, and individual patients.

A digital value network model for designing 'connected' value networks was developed, based on a framework proposed by Allee (2000), and key insights from the academic literature on digital technologies and emerging business models. The conceptual model was then used to explore alternative digital value network options and 'the potential for a patient centric, connected value network...for the 'personalised' treatment for a specific patient population' - the research objective of this study.

A mixed methodology involving both interviews and an online survey was employed to gather primary data, and to support the development of the conceptual model. Interviews captured the viewpoints of pharma organisations, device manufacturers, the UK's National Health Service (NHS) and academics, as well as emergent themes. Conversely, the survey sought to source a broader pool of data, and to represent the general public's views. Set within the boundaries of treating chronic diseases, the model was validated by an expert panel in the specific case of type 2 diabetes, building on the emerging domain of digital/loT-based business models in the academic literature.

The conceptual model demonstrates the potential relationships between the main stakeholders identified in the chronic care ecosystem (pharma, the NHS, device/tech companies, regulators and patients). It maps the generic relationships between stakeholders (data/revenue streams, knowledge flows, goods and serviceable aspects) made conceivable by, for example, the adoption of digital technologies and novel manufacturing processes. Application affords a theoretical example for the provision of 'personalised' treatment for a specific patient population. The model also aims to address some of the various disparities identified between stakeholders within the ecosystem. The final model presented was structured around a joint venture (JV) scenario involving the NHS and a wearable technology company. Future service network configuration options, the 'touch-point' processes for better network integration, and the data requirements in supporting the effective implementation of a series of service strategy scenarios were assessed. These scenarios included the adoption and use of health IT tools, social media, clinical decision support and business intelligence systems that specifically focus on extending 'concepts of operations' and service 'outcome' contracting models to an e-healthcare context. The model was also used to capture emerging distributed 'maketo-order' service models for pharmaceutical supply_driven by digital manufacturing (continuous processing, process analytics) and digital supply chain concepts.

Bureaucracy, regulations and legislation within the ecosystem were identified as key constraints. These, in combination with NHS's emphasis on cost effectiveness, highlighted the current 
difficulty for SMEs in entering the market. This raised a requirement for early communication and collaboration in establishing a mutually beneficial, connected network with the NHS/MHRA as early as possible to understand their requirements (for new connected devices/digital networks) and ensure a clear value proposal.

Contradicting industrial viewpoints on factors, such as which body should be at the centre of data collection will also lead to compromises having to be made. For a safe and secure system to ensure patients trust, data collected would need to be accurate, reliable and confidential, guaranteeing correct analysis and effective services. The responsibilities of ensuring safe infrastructure for collection, that sufficient resource would be available to deal with the data, and incentivising patients to use devices (correctly) would also be major challenges to overcome.

The disconnection between pharmaceutical companies and patients, identified in the literature review, was evident from the interviews. Currently, patients only provide feedback to pharma organisations during clinical trials and, discounting this, there is virtually no communication channels between the stakeholders. This was viewed, from the pharma sector perspective, as a great opportunity for emerging digital technologies to build more bi-directional relationships, enable the provision of remote services, and reduce patient discomfort. In terms of a disconnection/connection between pharma organisations and the NHS, the two bodies currently collaborate together relatively closely to develop drugs, negotiate acceptable prices, and control supply levels. However, perceived issues around competition and having "values and drivers [that] are very different" currently prohibit a more integrated relationship. Despite this, it was stressed that "there is a dialogue [with the NHS] to see how [pharma] can work together for the benefit of the patient", which could be facilitated via increased data collection/sharing.

From an academic perspective, the model builds on the literature and provides a novel base for additional research. Academics could apply the generic architecture in specific chronic illnesses, different healthcare systems and, potentially, other industrial contexts. As part of a future digital food research agenda, the model is being applied to assess a series of value propositions on how technology and data could facilitate the integration of other 'systems', for example, the integration of education, food, and social care. For example, the model could be adapted to monitor nutrition and/or allergies, enabling customers/carers to control their/their patient's diets, via personalised health advice, and for suppliers to improve the quality of their products.

The model also has an important role to play, in practice, in the exploration of current and future digital scenarios and business models. It can be applied to assess the relative attractiveness of potentially disrupting technology interventions in medicine manufacturing and e-healthcare management, ensuring consistent "like for like" business case comparisons. From a value creation standpoint, the model also has implications for practice as it captures numerous serviceable aspects and potential new business models, previously unidentified in literature. It demonstrates its capacity to be used as a strategic planning tool, enabling managers to better position their companies for a more digital future. The model also helps simplify the inevitable complexity of a digital environment, capturing the rigorous regulations, constraints and barriers to entry for those within, or aspiring to enter the market. A significant opportunity here to realise the full value of the model would be to collaborate and apply the model with specific organisations. Such cross-disciplinary collaboration would ideally include academia working with both the NHS and a leading technology company to explore the proposed JV detailed in the model. This would facilitate a more in-depth, company specific case study to map out an implementation plan for the required data collection and infrastructure.

A limitation of the study was potential ethical issues being raised by directly interviewing patients suffering from chronic disease. As chronic disease sufferers are generally older than the majority of the survey's demographic, only a limited number of respondents suffered from such a condition. As a result, the survey findings should be regarded as an insight into the perspective of patients in the near future, and not used to dictate how the system should operate at present. Further work could look to gain ethical approval, and acquire a more comprehensive understanding of patients' perspectives.

While the interview sample may be deemed as low, the eight expert panel interviewees presented us with interesting insights, opportunities for future research and - critically - access to their 
individual networks. Future research plans will include further test and refinement of the conceptual framework using a greater interview sample so that any future data is more accurately representative of the population sample. To further test the robustness of the model, additional research will focus on its application in a variety of chronic disease cases, or cell-based therapies where personalised treatment is vital - through accessing the international network of experts identified by the expert panel. As the study is predominantly focused on human factors, partnering with academics from the social sciences in this process may afford deeper insights. It was also suggested the model may be better suited to a more privatised market, where adherence could be more easily incentivised, thus, a case study of the US healthcare system is planned. We will explore the opportunities for Blockchain as a solution for securely sharing medical records, to tackle the issue of counterfeit drugs, or improve the productivity of drug development. This could have major implications for UK healthcare infrastructure and enable global pharma organisations to drive value and build trust. New governmental standards will likely be necessary to control factors such as access to and security of patient, inventory and service level data. We also aim to explore future policy implications as a direct result of digitalisation across different industries, and the new roles and responsibilities arising for regulators and other key stakeholders.

Acknowledgements: This research was supported by the Engineering and Physical Sciences Research Council (EPSRC) Centre for Innovative Manufacturing in Continuous Manufacturing and Crystallisation [grant number EP/1033459/1], and the UK Department of Business, Innovation and Skills (BIS) Advanced Manufacturing Supply Chain Initiative (AMSCI) funded project 'ReMediES' (Reconfiguring Medicines E2E Supply) [grant number TS/ L006529/1].

\section{References}

Ahluwalia, P., Gimpel, G. and Varshney, U. (2017) 'ICT interventions impacting big societal challenges: an electronic healthcare approach to homelessness', Int. J. Electronic Healthcare, Vol.8, No.2/3/4, pp.95-120. DOI: 10.1504/IJEH.2015.075352

Apostolakis, I., Koulierakis, G., Berler, A., Chryssanthou, A. and Varlamis, I. (2012) 'Use of social media by healthcare professionals in Greece: an exploratory study', Int. J. of Electronic Healthcare, Vol.7, No.2, pp.105- 124

Ahmadi, M. M. and Jullien, G. A. (2009) 'A Wireless-Implantable Microsystem for Continuous Blood Glucose Monitoring', IEEE TRANSACTIONS ON BIOMEDICAL CIRCUITS AND SYSTEMS, 3(3), pp. 169-180.

Ajai, O., Tiwari, A. and Alcock, J. R. (2009) 'Informatics-Based Product-Service Systems for Point-ofCare Devices', Proceedings of the 1st CIRP Product-Service Systems (IPS2) Conference, Cranfield University

Allee, V. (2000) 'Reconfiguring the Value Network', Journal of Business Strategy, Vol. 21, No. 4, pp.36-39

Årsand, E. et al. (2015) 'Performance of the First Combined Smartwatch and Smartphone Diabetes Diary Application Study', Journal of Diabetes Science and Technology, pp. 1-8.

Baines, T.S., Lightfoot, H.W., Benedettini, O, and Kay, J.M. (2009) 'The servitization of manufacturing; a review of literature', Journal of Manufacturing Technology Management, 20(5), pp. 547-567.

Barclay, R. (2014) Google Scientists Create Contact Lens to Measure Blood Sugar Levels in Tears, s.l.: HealthLine.

BBC News, 2014. Care.data: How did it go so wrong? London: BBC News.

Beni, J.B. (2011), 'Technology and the healthcare system: implications for patient adherence', Int. J. Electronic Healthcare, Vol.6, No.2/3/4, pp.117 - 137 
Bhartiya, S. and Mehrotra, D. 2015. An access control framework for secured sharing of electronic health records using hierarchy similarity analyser, Int. J. Electronic Healthcare, Vol.8, No.2/3/4, pp.121-141. DOI: 10.1504/IJEH.2015.075327

Brach, J.S. et al. (2005) 'Wearable feedback systems for rehabilitation', Journal of Neuroengineering and Rehabilitation, Vol. 2, No. 17, pp.

Burns, L.R. (2002) 'The Health Care Value Chain: Producers, Purchasers, and Providers'. 1st ed. s.I.: Jossey-Bass.

Butner, K. (2010) 'The smarter supply chain of the future'. Strategy \& Leadership, Vol. 38, No. 1, pp. 22-31.

Calia, E. (2010) 'The internet of things \& identity in the future internet', Wireless Personal Communications: An International Journal, Vol. 49, pp. 353-363.

Campbell, S.M., Roland, M.O. and Buetow, SA. (2000) 'Defining quality of care', Social Science and Medicine, Vol. 51, No. 11, pp. 1611-1625.

Champagne, D., Leclerc, O. and Hung, A. (2015) 'The road to digital success in pharma', s.l.: McKinsey Global Institute.

Chan, H. (2015) 'Internet of Things Business Models', Journal of Service Science and Management, Vol. 8, pp. 552-568.

Chan, M. et al. (2012) 'Smart wearable systems: Current status and future challenges', Artificial Intelligence in Medicine, Vol. 56, No. 3, pp. 137-156.

Chen, L., Long, J. and Yan, T. (2004) 'E-supply chain implementation strategies in a transitional economy', International Journal of Information Technology and Decision Making, Vol. 3, No. 4, pp. 563-574.

Comstock, J. (2014) 'FDA clears two wristworn fitness trackers for clinical trials', s.l.: MobiHealthNews - HIMSS Media.

Dadgar, M. and Joshi, K.D. (2017) 'Value-sensitive review and analysis of technology-enabled selfmanagement systems: a conceptual investigation', Int. J. Electronic Healthcare, Vol. 9, No.2/3, pp.157-185. DOI: 10.1504/IJEH.2017.10003175

Daly, R., Harrington, T.S., Martin, G.D. and Hutchings, I.M. (2015) 'Inkjet printing for pharmaceutics A review of research and manufacturing', International Journal of Pharmaceutics, Vol. 494, No. 2, pp. 554-567.

Dijkman, R.M., Sprenkels, B., Peeters, T. and Janssen, A. (2015) 'Business models for the Internet of Things', International Journal of Information Management, Vol. 35, No. 6, pp. 672-678.

Dohr, A. et al. (2010) 'The Internet of Things for Ambient Assisted Living'. s.I., 7th International Conference on Information Technology: New Generations.

Doukas, C. and Maglogiannis, I. (2012) 'Bringing loT and Cloud Computing towards Pervasive Healthcare'. s.l., Proceedings - 6th International Conference on Innovative Mobile and Internet Services in Ubiquitous Computing, IMIS 2012.

ECIS (2009) 'Internet of Things Strategic Research Roadmap', s.I.: European Commission Information Society.

Edwards, P.J. (2009) 'Value Networks Identify Innovation in 21st Century Pharmaceutical Research', Drug Discovery Today, Vol. 14 Nos. 1-2, pp. 68-77. DOI:10.1016/j.drudis.2008.09.015. 
EPSRC (2013) Redistributed Manufacturing Workshop Report, s.l.: Engineering and Physical Sciences Research Council.

Fan, P. and Zhou, G. (2011) 'Analysis of the business model innovation of the technology of internet of things in postal logistics', s.l., 2011 IEEE 18th International Conference on Industrial Engineering and Engineering Management.

Gläser, J. and Laudel, G. (2013) 'Life With and Without Coding: Two Methods for Early-Stage Data Analysis in Qualitative Research Aiming at Causal Explanations", Qualitative Social Research, Vol. 14, No. 2. Available at: http://nbn-resolving.de/urn:nbn:de:0114-fqs130254 (accessed 8/8/2017)

Gupta, A.K., Tesluk, P.E. and Taylor, M.S. (2007) 'Innovation At and Across Multiple Levels of Analysis', Organization Science, Vol. 18, No. 6, pp. 885-897.

Halvorson, M. (2007) 'A Pilot Trial in Pediatrics with the Sensor-Augmented Pump', Journal of Pediatrics, pp. 103-106.

Harrington, T.S. and Srai, J.S (2012) 'Defining product-service network configurations and location roles: a current and future state analysis framework for international engineering operations', International Journal of Product Development, Vol. 17, Nos. 3/4, pp. 228-253. DOI:

10.1504/IJPD.2012.052103

Harrington, T.S and Srai, J.S. (2016) 'Designing a 'concept of operations' architecture for nextgeneration multi-organisational service networks', Al and Society: Journal of Knowledge, Culture and Communication, Published online: 17 May. DOI: 10.1007/s00146-016-0664-5

Harrington, T.S and Srai, J.S. (2017) 'Understanding stages of supply network emergence in technology commercialisation', International Journal of Manufacturing Technology and Management. DOI: 10.1504/IJMTM.2016.10000001

Harrington, T.S., Phillips, M.A., and Srai, J.S. (2017) 'Reconfiguring global pharmaceutical value networks through targeted technology interventions', International Journal of Production Research. Published online. DOI: 10.1080/00207543.2016.1221541

Harrington, T.S, et al (2016) 'Identifying design criteria for urban system 'last-mile' solutions - a multistakeholder perspective', Production Planning and Control, Vol. 27, No. 6, pp. 456-476. DOI: 10.1080/09537287.2016.1147099

Howells, J. (2000) 'Innovation \& services: New conceptual frameworks', s.l.: Centre for Research on Innovation and Competition at The University of Manchester.

Ilioudi, S., Lazakidou, A. and Tsironi, M. (2010), 'Information and communication technologies for better patient self-management and self-efficacy', Int. J. Electronic Healthcare, Vol.5, No.4, pp.327 339

Jeansson, J.S. (2013) 'Benefits negotiation: three Swedish hospitals pursuit of potential electronic health record benefits', Int. J. of Electronic Healthcare, 2013 Vol.7, No.3, pp.248 - 268

Jean, B.R., Green, E.C. and McClung, M.J. (2008) 'A Microwave Frequency Sensor for Non-Invasive Blood-Glucose Measurement', Atlanta, GA, IEEE Sensors Applications Symposium.

Jimenez, J. (2015) 'Novartis on digitizing medicine in an aging world', s.I.: McKinsey \& Company.

Kang, G. (2012) 'Wireless eHealth (WeHealth) --- From Concept to Practice'. s.l., IEEE 14th International Conference on e-Health Networking, Applications and Services (Healthcom).

Köbler, F. et al. (2009) 'Analysis of Value Creation through Product-Service-Systems in the German Medical Engineering Industry', Berlin, Proceedings First International Symposium on Services Science ISSS'09. 
Ko, M. et al. (2014) 'Design and analysis of wearable pupillometer for autonomic neuropathy of diabetic patients', Applied Optics, Vol. 53, No. 29, pp. 27-34.

Kohlbacher, F. (2005) 'The Use of Qualitative Content Analysis in Case Study Research, Qualitative Social Research, 7(1). Available at: http://nbn-resolving.de/urn:nbn:de:0114-fas0601211 (accessed 8/8/2017)

Krishnamurthy, G. (2013) 'Non-Invasive Measurement of Blood Glucose Levels Using GlucoTrack: Interview with CEO Avner Gal', s.I.: medGadget.

Le, T., Wilamowska, K., Demiris, G. and Thompson, H. (2012) 'Integrated data visualisation: an approach to capture older adults' wellness', Int. J. of Electronic Healthcare, 2012 Vol.7, No.2, pp.89 104

Lee, H. et al. (2016) 'A graphene-based electrochemical device with thermoresponsive microneedles for diabetes', Nature Nanotechnology.

Lee, S.L. et al. (2015) 'Modernizing Pharmaceutical Manufacturing: from Batch to Continuous Production', Journal of Pharmaceutical Innovation, Vol. 10, pp. 191-199.

Liu, L. and Jia, W. (2010) 'Business Model for Drug Supply Chain Based on the Internet of Things'. s.l., Proceedings of Network Infrastructure and Digital Content, 2010.

Midha, V., Ngafeeson, N. and Ghosh, K. (2017) 'Special Issue on Healthcare IT: Current Research and Future Trends', Int. J. Electronic Healthcare, Vol. 9 No. 2/3, pp.89-99.

Manyika, J. et al. (2013) 'Disruptive Technologies: Advances that Will Transform Life, Business, and the Global Economy', s.l.: McKinsey \& Company.

Mittermeyer, S.A., Njuguna, J.A. and Alcock, J.R. (2011) 'Product-Service Systems in Health Care: Case Study of a Drug-Device Combination', International Journal of Advanced Manufacturing Technology, Vol. 52, Nos. 9-12, pp. 1209-1221.

Mont, O.K. (2002) 'Clarifying the concept of product-service system', Journal of Cleaner Production, Vol. 10, pp. 237-245.

More, R. (2001) 'Creating profits from integrated product-service strategies', s.I.: Ivey Business Journal.

Narayana, S.A., Kumar Pati, R. and Vrat, P. (2014) 'Managerial research on the pharmaceutical supply chain - A critical review and some insights for future directions', Journal of Purchasing and Supply Management, Vol. 20, No. 1, pp. 18-40.

Neely, A. (2007) 'The Servitization of Manufacturing: an Analysis of Global Trends', 14th European Operations Management Association Conference. Ankara, Turkey

Neely, A. (2009) 'Exploring the financial consequences of the servitization of manufacturing', Operations Management, Vol. 1, pp. 103-118.

Neithercott, T. (2015) 'Monitor Your Glucose with the Apple Watch', s.I.: American Diabetes Association.

Osterwalder, A. and Pigneur, Y. (2010) 'Business model generation: a handbook for visionaries, game changers, and challengers', 1st ed. Hoboken, NJ: John Wiley \& Sons.

Pedroso, M.C. and Nakano, D. (2009) 'Knowledge and information flows in supply chains: A study on pharmaceutical companies', International Journal of Production Economics, Vol. 122, No. 1, pp. 376384. 
Peeples, M., Melfi, R., O'Keefe, D. and Macleod, J. (2015) 'Blue Star...Transform Your DSME/S Program- Leverage the Value of Mobile Health'. s.l., American Association of Diabetes Educators.

Peppard, J. and Rylander, A. (2006) 'From Value Chain to Value Network: Insights for Mobile Operators', European Management Journal, Vol. 24, Nos. 2-3, pp. 128-141.

Phillips, M.A., Harrington T.S. and Srai, J.S (2017) 'Convergent innovation in emerging healthcare technology ecosystems: addressing complexity and integration', Technology Innovation Management Review (in press)

Porter, M E. (1980) 'Competitive Strategy', New York: Free Press.

Porter, M.E. (2005) 'Redefining health care: Creating value-based competition on results', Atlantic Economic Journal, Vol. 35, No. 4, pp. 491-501.

Puustjarvi, J. and Puustjarvi, L. (2011) 'Personal Health Ontology: towards the interoperation of ehealth tools', Int. J. Electronic Healthcare, Vol. 6, No.1, pp.62 -75

Rahmani, A.-M.et al. (2015) 'Smart e-Health Gateway: Bringing Intelligence to Internet-of-Things Based Ubiquitous Healthcare Systems', s.I., 2015 12th Annual IEEE Consumer Communications and Networking Conference.

Rodgers, M.M., Pai, V.M. and Conroy, R.S. (2015) 'Recent Advances in Wearable Sensors for Health Monitoring', IEEE SENSORS JOURNAL, Vol. 15, No. 6, pp. 3119-3126.

Ryan, L., Tormey, D. and Perry, S. (2014) 'Cultural Barriers to the Transition from Product to ProductService in the Medical Device Industry', International Journal of Service Science, Management, Engineering, and Technology, Vol. 5, No. 2, pp. 36-50.

Sahu, M., Grover, A. and Joshi, K.D. (2014) Role of mobile phone technology in health education in Asian and African countries: a systematic review, Int. J. of Electronic Healthcare, Vol. 7, No.4, pp.269 $-286$

Samhan, B and Joshi, K.D. (2017) 'Understanding electronic health records resistance: a revealed causal mapping approach', Int. J. Electronic Healthcare, Vol. 9, No.2/3, pp.100-128. DOI: 10.1504/IJEH.2017.10003173

Settanni, E., Harrington T.S, Srai, J.S. (2017) 'Pharmaceutical supply chain models: A synthesis from a systems view of operations research', Operations Research Perspectives, Vol 4. pp. 74-95. DOI: 10.1016/j.orp.2017.05.002

Shah, N. (2004) 'Pharmaceutical supply chains: Key issues and strategies for optimisation', Computers and Chemical Engineering, Vol. 28, Nos. 6-7, pp. 929-941.

Srai, J.S. and Alinaghian, L.S. (2013) 'Value chain reconfiguration in highly disaggregated industrial systems: examining the emergence of healthcare diagnostics', Global Strategy Journal, Vol. 3, pp. 88108.

Srai, J.S. (2014) 'Twenty-first Century Supply Chains: Transforming the Pharmaceutical Industry', Cambridge, UK: Institute for Manufacturing Review.

Srai, J.S. et al. (2015) 'Future Supply Chains Enabled by Continuous Processing-Opportunities and Challenges', Continuous Manufacturing Symposium. s.l., Wiley Online Library.

Srai, J.S. Christodoulou, P. and Harrington, T.S. (2014) 'Configuring global value networks within industrial ecosystems' [Online].

Srai, J.S., Harrington, T.S., Alinaghian, L.S. and Phillips, M.A. (2015) 'Evaluating the potential for the continuous processing of pharmaceutical products - a supply network perspective', Chemical Engineering and Processing: Process Intensification, Vol. 97, pp. 248-258. 
Srai J.S, Harrington T.S. and Tiwari M.K. (2016) 'Characteristics of redistributed manufacturing systems: a comparative study of emerging industry supply networks', International Journal of Production Research. Published online: 12 August. DOI: 10.1080/00207543.2016.1214765

Srai, J.S. (2017) 'Mapping industrial systems - a supply network perspective on enabling technologies, processes and actors', International Journal of Manufacturing Technology and Management, Vol. 31, No. 1-3, pp. 82-99. DOI: 10.1504/IJMTM.2017.082019

Steinbrook, R. (2008) 'Personally Controlled Online Health Data - The Next Big Thing in Medical Care?' The New England Journal of Medicine, pp. 1653-1656.

Sun, Y. et al. (2012) 'A holistic approach to visualizing business models for the internet of things', Communications in Mobile Computing, Vol. 1, No. 4, pp. 1-7.

Takahashi, M. et al. (2012) 'A Transdermal Continuous Glucose Monitoring System with an Implantable Fluorescent Hydrogel Fiber and a Wearable Photo-Detector', 16th International Conference on Miniaturized Systems for Chemistry and Life Sciences. Okinawa, Japan

Taylor, K. (2015) 'Connected health: How digital technology is transforming health and social care', s.l.: Deloitte.

Taylor, P. (2014) 'Wearing it well: the healthcare potential of wearable technology', s.I.: PMLive.

Tierney, M. J. et al. (2001) 'Clinical evaluation of the GlucoWatch® biographer: a continual, noninvasive glucose monitor for patients with diabetes', Biosensors and Bioelectronics, Vol. 16, pp. 621629.

Velikanov, I., Macintrye, M. and Angelis, J. (2013) 'Service Strategy Transition - Product and Service Offerings in Medical Devices', Proceedings of the European Operations Management Association (EurOMA) Conference 2013. Dublin

Wang, Q., Chen, W. and Markopoulos, P. (2014) 'Literature Review on Wearable Systems in Upper Extremity Rehabilitation', Valencia, IEEE-EMBS International Conference.

Yang, G. et al. (2014) 'A Health-loT Platform Based on the Integration of Intelligent Packaging, Unobtrusive Bio-Sensor, and Intelligent Medicine Box', IEEE Transactions on Industrial Informatics, Vol. 10, No. 4, pp. 2180-2191.

Yip, M.H., Phaal, R. and Probert, D.R. (2015) 'Characterising product-service systems in the healthcare industry', Technology in Society, Vol. 43, pp. 129-143.

Zhou, L., Chong, A.Y. and Ngai, E.W. (2015) 'Supply chain management in the era of the internet of things'. International Journal of Production Economics, Vol. 159, pp. 1-3. 


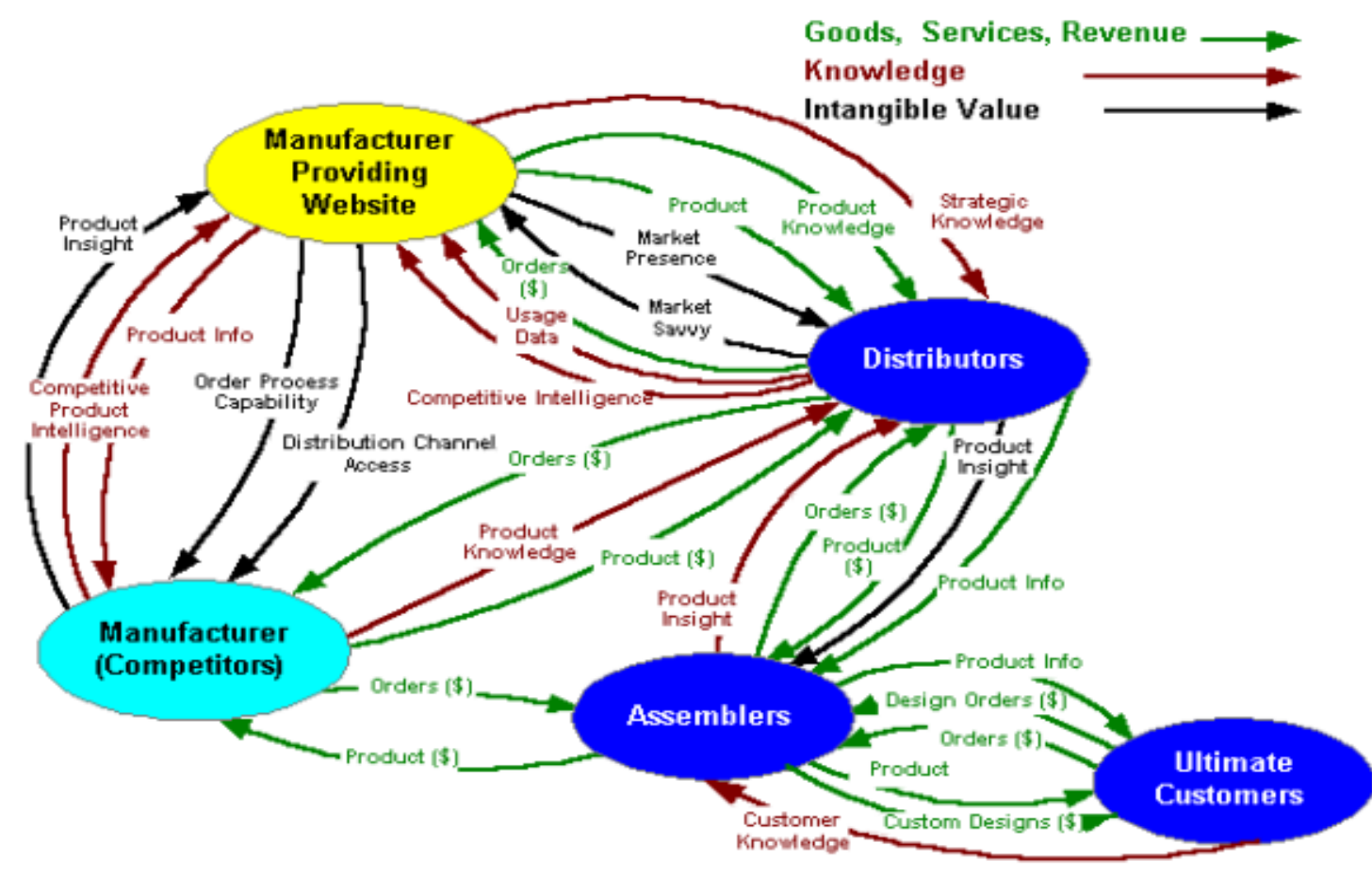

Appendix II. Interviewees and semi-structured interview questions (industry focus)

\begin{tabular}{|l|l|l|l|}
\hline Interview & Organisation & Role & Focus \\
\hline Pilot & Multi-national pharma & Senior manager & Pharma \\
\hline S1-1 & $\begin{array}{l}\text { Wearable-devices start- } \\
\text { up }\end{array}$ & $\begin{array}{l}\text { Lead engineer/ } \\
\text { director }\end{array}$ & Wearables/technology \\
\hline S1-2 & $\begin{array}{l}\text { Independent pharma } \\
\text { consultancy }\end{array}$ & $\begin{array}{l}\text { Director/senior } \\
\text { consultant }\end{array}$ & Pharma/pharmacy \\
\hline S1-3 & NHS & Professor/GP & Healthcare \\
\hline S1-4 & Multi-national pharma & Senior manager & Pharma supply chain \\
\hline S1-5 & NHS/university & $\begin{array}{l}\text { Clinical } \\
\text { researcher/GP }\end{array}$ & $\begin{array}{l}\text { Healthcare/devices } \\
\text { Regulation }\end{array}$ \\
\hline S1-6 & NHS/university & Professor/GP & Healthcare \\
\hline S1-7 & Multi-national pharma & Senior manager & Pharma/devices \\
\hline S1-8 & NHS/university & $\begin{array}{l}\text { Professor/senior } \\
\text { manager/GP }\end{array}$ & Healthcare/technology \\
\hline S2 & Multi-national pharma & Senior manager & Pharma \\
\hline
\end{tabular}


Pre-Interview Questions:

Record interview time/date

1. Confirm they are comfortable with the interview being recorded

2. Names, welcome etc.

3. My background

4. Project overview, key focus areas and aims/objectives

5. Overview of confidentiality

General Company Information Questions:

1. Please give a brief overview of yourself:

a. Current role

b. Time in role(s)

c. Industrial experience

2. Please give a brief overview of your company:

a. Main focus/company type

b. Key chronic illness related products/services

Problems with Current Industry Questions:

1. Discuss what you see as the main drivers in the pharmaceutical industry?

2. What inefficiencies/problems do you see in the industry?

3. Describe any disconnect you see between pharma and patients?

4. Describe any disconnect you see between pharma and the NHS?

5. Do you believe the pharma industry could benefit from these gaps being connected? Please discuss.

Data Gathering and Use Questions:

Introduce wearable/digital technologies in the treatment of chronic diseases (sweat patch).

1. Has your company considered the use of wearable-technologies to improve the treatment of chronic disease? Why? Discuss what value this could create.

2. Discuss who you see owning the data collected from a wearable-device? Could this cause legal issues?

3. Would your company consider purchasing data from patients if they own their data? Why/Why not?

4. Would your company prefer to collect/process patient data yourselves, or rely on others? Discuss the pros/cons of both.

Services/Business Model Based Questions:

Introduce the concept of PSSs in healthcare/pharma.

1. Is your company looking to adopt a more services based, patient-centric business model? Give details/examples.

2. Discuss the services your company could offer to patients if you were able to collect data regarding their illness.

3. Discuss the feasibility/key challenges in offering said services from both business and technical perspectives.

4. Would your company be interested in collecting/processing/selling patient data as a service to the NHS? What if it was for profit?

5. Would your company be interested in purchasing processed data from the NHS as services?

6. Would your company be interested in any of the data collection finance models shown on the hand out? Why?

Potential New System Questions:

Show and talk through the prototype model.

1. Could you discuss any issues/recommendations you see with the model? Do you agree with the B2B/B2C serviceable aspects?

2. Please discuss the major challenges in order for this type of network to be developed?

3. What do you see as the best approach going forward to facilitate the connection of healthcare and pharmaceutical value chains?

\section{Wrap Up Questions:}

1. Is there anything else you would like to add?

2. Would you be happy for follow up questions/clarification? 
Appendix III. On-line survey design

\section{Page 1. Welcome}

Please answer the following questions from the perspective that you are affected by a chronic illness (such as Diabetes). This survey is for research purposes only. The data you provide will be anonymous and will not be disclosed to others.

\section{Page 2. Wearable Technology Questions}

Q1. Which of the following features would be essential for a data collection device used to monitor your condition? (Please select all that are relevant)

\section{Light weight}

Non-invasive

Comfortable to wear

Long battery life ( $>1$ day)

Waterproof and robust to survive daily activities

Non-visible through clothes

Stylish design

Automatic (i.e. does not require user input to operate)

Connect to mobile phone/smart watch to show user data

I would not be happy wearing a data collection device

Other (please specify):

Q2. Please select your preferred style of wearable data collection device:

Wearable patch (on skin)

Contact lens with incorporated sensing technology

Embedded sensor (under skin) wired to external device (glucometer for diabetes)

Embedded sensor (under skin) wirelessly communicating data to smart phone/watch

I would not be happy wearing a data collecting patch/device

Q3. Would you also be comfortable with the device automatically administering your medication (Assuming it was reliable, accurate and painless)?

Yes

No

\section{Page 3. Data Collection Questions}


Q4. Which of the following types of data would you be comfortable with the named institutions/companies collecting? (Please select all that are relevant)

\begin{tabular}{|c|c|c|c|}
\hline The NHS & $\begin{array}{l}\text { Pharma } \\
\text { Companies }\end{array}$ & $\begin{array}{l}\text { Wearable Device } \\
\text { Manufacturers }\end{array}$ & $\begin{array}{l}\text { Independent Data } \\
\text { Collection } \\
\text { Companies }\end{array}$ \\
\hline
\end{tabular}

Specific condition data

(i.e. blood glucose data)

Emergency data (i.e.

hypoglycaemic event

data)

Medication compliance

data

Other health data (heart

rate, diet, age, gender

etc.)
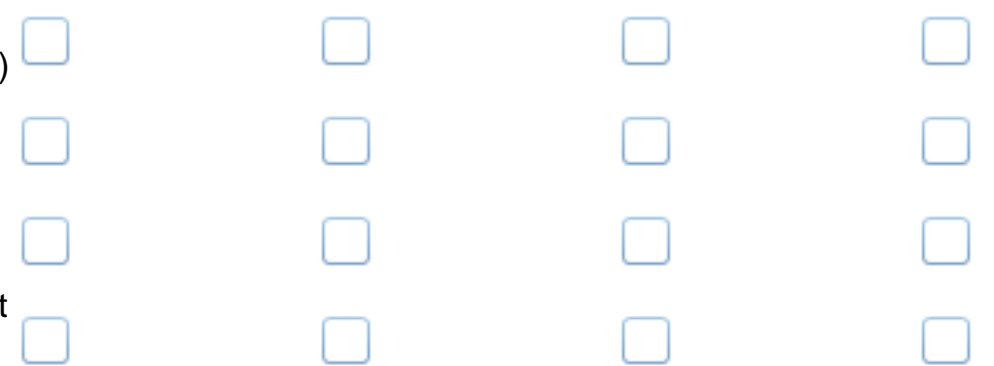

Q5. For which of the following purposes would you be comfortable with the named institutions/companies using your data? (Please select all that are relevant)

The NHS

To better manage/treat your condition

To learn more about the condition for the treatment

of the general public

To process your data in order to offer

information/services to

other companies
Pharma Companies

Q6. Please rank the following outcomes of using a wearable data collection device in order of importance (with 1 being the most important):

The data is anonymised and cannot be used to identify you The data is only used by companies you are made aware of To help improve your condition through better management/treatment The data is used and stored securely

You receive a fee for your data

To help improve your condition through personalised medicine

To gain a better understanding of the condition to help others

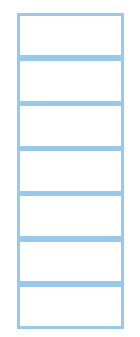

\section{Page 4. Services Questions}

Q7. Would you be comfortable receiving any of the following remote services from the named institutions/companies, based on your data? (Please select all that are relevant)

The NHS

Pharma Companies

Customised medication

Medication dose reminders 
External health data analysis and advice (personalised treatment) Personalised improvement reporting

Remote condition monitoring and appropriate emergency response

Q8. On what financial basis would you be happy to receive the previously selected services from the named institutions/companies? (Assuming they were reasonably priced and offered more effective treatment than the standard)

Yes, I would pay a reasonable fee for remote services
No, I would only accept No, I would not accept free remote services remote services

The NHS

Pharma Companies

Q9. Would you be comfortable with any of the following companies/institutions benefiting financially from your data?

The NHS

Pharma Companies

Wearable Device Manufacturers

Independent Data Collection Companies

I would not be happy for any company/institution to benefit financially from my data

Q10. If pharma companies and the NHS were to partner in a new initiative to tackle chronic conditions, which arrangements would you be comfortable with? (Please select all that are relevant)

Free wearable device, free services, payment (to you) for data collection

Free wearable device, free services, no payment (to you) for data collection

Free wearable device, chargeable services, payment (to you) for data collection

Free wearable device, chargeable services, no payment (to you) for data collection

Chargeable wearable device, free services, payment (to you) for data collection

Chargeable wearable device, free services, no payment (to you) for data collection

Chargeable wearable device, chargeable services, payment (to you) for data collection

Chargeable wearable device, chargeable services, no payment (to you) for data collection

I would not be happy with any of these 


\section{Page 5. Final General Questions}

Q11. Please state the gender you identify as:

Male

Female

Prefer not to say

Q12. Please state your age group:

$<10$

10-19

20-29

30-39

40-49

50-59

$60+$

Prefer not to say

Q13. Please state which type(s) of chronic Illness you currently have/had: (Please select all that are relevant)

Type 1 Diabetes

Type 2 Diabetes

Gestational Diabetes

I do not suffer from a chronic condition

Prefer not to say

Other (please specify):

Q14. Do you agree with any of the following statements regarding your condition? (Please select all that are relevant)

It is or was easy for you to forget when to take medication and you would benefit from reminders Medication is or was awkward and/or unpleasant to take

Travelling to doctors for check-ups is or was inconvenient

You feel you would or would have benefited from more tailored treatment

You would feel more secure knowing health emergencies could be detected and addressed immediately

You do not or did not take medication for your condition 
You have not suffered from a chronic condition

Q15. If there is anything else you would like to add please do so here: 